\title{
FORCE-DERIVATIVE FEEDBACK SEMI-ACTIVE CONTROL OF BASE-ISOLATED BUILDINGS USING LARGE-SCALE MR FLUID DAMPERS
}

\author{
A. Rodríguez \\ Structural Department, Alstom-Power Wind, Ecotecnia Energías Renovables S.L., \\ Roc Boronat, 78, 08005 Barcelona, SPAIN \\ A. Bahar \\ CoDAlab, Departament de Matemàtica Aplicada III, Universitat Politècnica de Catalunya (UPC), \\ Jordi Girona, 31, 08034 Barcelona, SPAIN \\ F. Pozo \\ CoDAlab, Departament de Matemàtica Aplicada III, Escola Universitària d'Enginyeria Tècnica \\ Industrial de Barcelona (EUETIB), Universitat Politècnica de Catalunya, \\ Comte d'Urgell, 187, 08036 Barcelona, SPAIN \\ francesc.pozo@upc.edu

\section{Acho} \\ CoDAlab, Departament de Matemàtica Aplicada III, Escola Universitària d'Enginyeria Tècnica \\ Industrial de Barcelona (EUETIB), Universitat Politècnica de Catalunya, \\ Comte d'Urgell, 187, 08036 Barcelona, SPAIN \\ Y. Vidal \\ CoDAlab, Departament de Matemàtica Aplicada III, Escola Universitària d'Enginyeria Tècnica \\ Industrial de Barcelona (EUETIB), Universitat Politècnica de Catalunya, \\ Comte d'Urgell, 187, 08036 Barcelona, SPAIN \\ J. Rodellar \\ CoDAlab, Departament de Matemàtica Aplicada III, Universitat Politècnica de Catalunya (UPC), \\ Jordi Girona, 31, 08034 Barcelona, SPAIN
}

\begin{abstract}
This paper investigates the effectiveness of force-derivative feedback semi-active control control scheme for seismic protection of base-isolated building structures employing magnetorheological (MR) fluid dampers. The base-isolation of the building is considered linear and represented by elastomeric bearings. Elastomeric bearings provide a clear advantage due to manufacturing development and long term efficacy if they are protected to environmental exposure. However, this type of isolation does not supply any energy dissipation to the building under seismic excitations because they lack of a hysteretic component like lead-rubber bearings. Nevertheless, these devices have one inadequacy when it comes to a near-fault earthquake, which is the high potential for excessive displacement at the base, producing total shear failure of the bearing. In the last years there has been an increasing interest to MR dampers and their applications to civil engineering structures. Base-isolated structures employing MR fluid dampers have gained the attention of many researchers in this field. These devices are highly nonlinear and thus accurate models of these devices are important for effective simulation and control system design. A hysteretic model based on the normalized Bouc-Wen model represents an experimentally identified large-scale MR fluid damper. The MR fluid damper is scaled up to represent both a real-manufacturable MR fluid damper and a compatible benchmark damper. The performance of the proposed force-derivative feedback semi-active control algorithm at the base-isolated building employing MR fluid damper is compared with passive-off, passive-on and clipped-optimal controllers. The proposed control scheme reduces the base-displacement without increasing the floor accelerations. Its main advantage is that only requires local measurements. The proposed MR fluid damper could be considered as a promising candidate for a real application of a base-isolated building employing MR fluid dampers as semi-active devices.
\end{abstract}

KEY WORDS: semi-active control; MR fluid damper; smart base isolated buildings; near-fault earthquakes; hysteresis 


\section{Introduction}

Structural control systems have shown great interest in the last decades for hazard mitigation in civil structures (Housner et al., 1997). Passive control systems have been widely used to mitigate vibrations due to external dynamic loadings (Soong and Dargush, 1997). However, passive control systems show some limitations in reducing structural demands once the excitation forces surpass some ranges assumed during the design stage of the structural system. Thus, engineers started to consider active control strategies used in other engineering fields (Pozo et al., 2006; Pozo et al., 2008). The main advantage of these active control schemes is their adaptability to different dynamic loadings by implementing a control law. However, these systems require a large power source, which is highly likely to be unavailable during extreme natural and/or man-made hazard. At the same time, active control systems inject energy to the systems and this lack of robustness may cause significant problems during an extreme dynamic load event. Therefore, semi-active control strategies have received significant attention in recent years because they cannot inject mechanical energy into the system, they do not require a significant power source to operate, they are controllable, and the bounded-input bounded-output stability is guaranteed (Luo et al., 2001; Pozo et al., 2009; Soong and Spencer, 2002). Moreover, semi-active controllers in hybrid base-isolation systems can achieve almost the same performance as an active base isolation system in protecting the safety of building against strong earthquakes (Li and $\mathrm{Ou}, 2006)$.

In this paper we firstly consider linear elastomeric rubber bearings with low damping as the base isolation system, which is the most widely used type of base isolation worldwide. The experimentally identified 20 $\mathrm{kN}$ magnetorheological fluid damper, which is used as a semi-active device, is scaled up to both a real manufacturable $400 \mathrm{kN}$ magnetorheological damper and to a $2000 \mathrm{kN}$ MR damper as proposed in the smart-base isolated benchmark building (Narasimhan et al., 2006). These MR dampers are represented using the normalized Bouc-Wen model (Ikhouane and Rodellar, 2007). Because the force generated in the MR dampers is dependent on the local responses of the structural system, the desired control force cannot always be produced by the devices. Only the control current or voltage can be directly controlled to increase or decrease the force produced by the devices. The desired control force is based on an active force-derivative feedback controller. From a theoretical point of view, the force which has to be supplied by the actuator is based on the measured force which is currently applied by the MR damper. In general, in the semi-active control strategies presented in the literature, for instance (Jung et al., 2006; Zapateiro et al., 2009; Zapateiro et al., 2009), they managed a single MR damper per floor or, in the case of multiple MR dampers, they receive the same command current. In this work, a new practical method (Bahar et al., 2010a; Bahar et al., 2010b) has been used to compute the command current of each MR damper independently according to the desired control force. The management of these MR dampers is based on a hierarchical strategy: we first compare the total damping force generated in the MR dampers with respect to the desired control force and then we decide what dampers need to apply more damping force and the corresponding command current. The whole method is simulated by considering a three-dimensional smart base-isolated benchmark building (Narasimhan et al., 2006) where the MR dampers are used as supplemental damping devices. This benchmark problem is a new generation of benchmark studies by the American Society of Civil Engineering (ASCE) Structural Control Committee, that offers a carefully modeled real-world structure in which different control strategies can be implemented and compared.

The paper is structured as follows. In Section 2, the experimental setup to identify a real large-scale magnetorheological fluid damper is presented. We also present in Section 3 the magnetorheological damper model. Section 4 is dedicated to designing the force-derivative feedback semi-active control algorithm and it is divided into five subsections: Subsection 4.1 presents the dynamic model of the base-isolated structure; Subsection 4.2 describes the desired control force which is based on a force-derivative feedback controller for hysteretic base-isolated structures. The inverse model that provides a suitable context to compute the command current of MR dampers analytically is described in Subsection 4.3; meanwhile the algorithm for selecting the command signal is concisely stated in 
Subsection 4.4. Some practical issues on the implementation of the hierarchical semi-active control are presented in Subsection 4.5. The smart base-isolated structure that serves as a benchmark problem for numerical testing is presented in Section 5. Numerical simulations to analyze the performance of the proposed hierarchical semi-active scheme are presented in Section 6. Final comments are given in Section 7.

\section{Experimental Setup}

In this section, we present the experimental setup to identify a real large-scale magnetorheological (MR) fluid damper. The analytical model of this mechanism will be then used as a semi-active device in the numerical simulations in the benchmark platform.

The large-scale magnetorheological (MR) damper in Figure 1 was used to carry out experimental tests at Kinki University (Osaka, Japan). This MR damper has two by-pass flow portions, which work using low currents (up to $0.2 \mathrm{~A}$ ); it has a maximum nominal force of $20 \mathrm{kN}$ and a stroke of $\pm 100 \mathrm{~mm}$. Moreover, this MR damper is double-ended, which is a major advantage in the mechanical design compared to a single-ended piston MR dampers. This advantage minimizes the MR fluid property change due to the small volume change inside the chamber. The maximum velocity is $188 \mathrm{~mm} / \mathrm{s}$. Its main characteristics are shown in Table I.

Table I. Large-scale MR fluid damper characteristics

\begin{tabular}{ll}
\hline \multicolumn{1}{c}{ Parameters } & Value \\
\hline Maximum force (nominal) & $20 \mathrm{kN}$ \\
Stroke & $\pm 100 \mathrm{~mm}$ \\
Cylinder bore & $95 \mathrm{~mm}$ \\
Orifice size & $2 \mathrm{~mm}$ X $20 \mathrm{~mm}$ \\
Coil & $2 \mathrm{with} 3800 \mathrm{turns}$ \\
MR fluid & MRF-132LD (LORD Corp.) \\
Inductance & $1.5 \mathrm{H}$ \\
Coil resistance & $60 \Omega$ \\
Maximum current & $0.3 \mathrm{~A}$ \\
\hline
\end{tabular}

\section{Overall System}

The MR damper was tested using a hydraulic actuator (Figure 2) capable of generating a maximum nominal force of $30 \mathrm{kN}$. The force and displacement measurements were done using a $30 \mathrm{kN}$ load cell and a $\pm 100 \mathrm{~mm}$ LVDT sensor. A section of the MR damper is shown in Figure 3. This MR damper has a reservoir tank instead of an accumulator in order to supply MR fluid when required and the coils are situated outside the main case. The electric circuit detail of the MR damper is shown in Figure 4. 


\section{The Magnetorheological Damper Mode}

The normalized version of the Bouc-Wen model (Ikhouane et al., 2005) is an equivalent representation of the original Bouc-Wen model (Wen, 1976). For MR dampers in shear mode it takes the form:

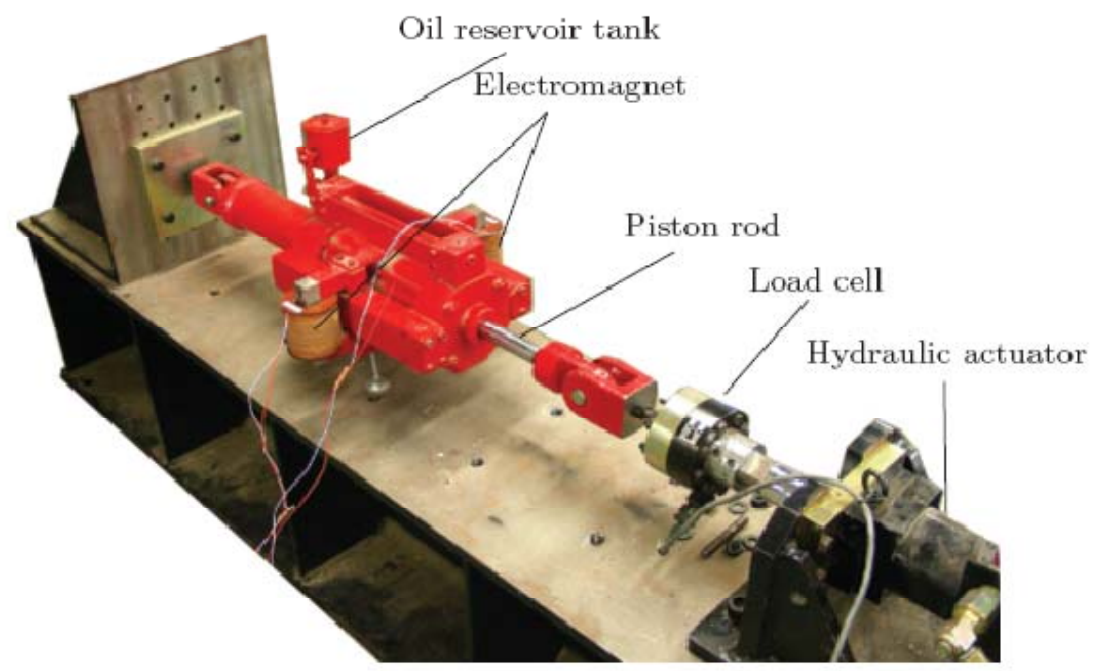

Figure 1. $20 \mathrm{kN}$ MR fluid damper

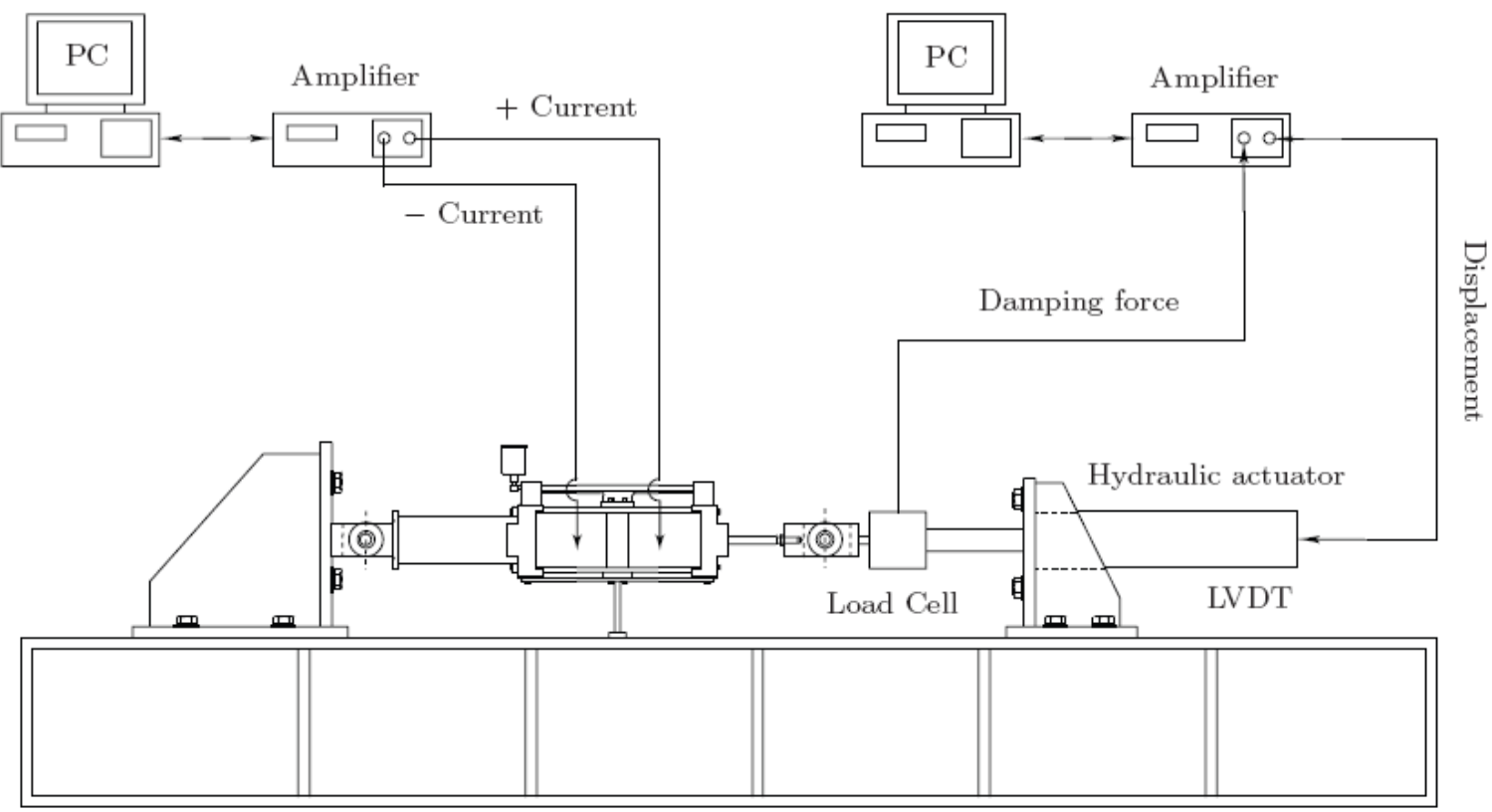

Figure 2. MR damper setup

$$
\begin{gathered}
F_{M R}(t)=\kappa_{\dot{x}} \dot{x}(t)+\kappa_{w} w(t), \\
\dot{w}(t)=\rho\left(\dot{x}(t)-\sigma|\dot{x}(t) \| w(t)|^{n-1} w(t)+(\sigma-1) \dot{x}(t)|w(t)|^{n}\right),
\end{gathered}
$$


where $F_{M R}$ is the output force of the MR damper, and $\dot{x}(t)$ is the velocity. The system parameters, which are current-dependent, are $\kappa_{\dot{x}}(i)>0, \kappa_{w}(i)>0, \rho(i)>0, \sigma(i)>1 / 2$, and $n(i) \geq 1$. These parameters control the shape of the hysteresis loop and their meaning can be found in (Ikhouane et al., 2007). The state variable $w(t)$ has not a physical meaning so that it is not accessible to measurements.
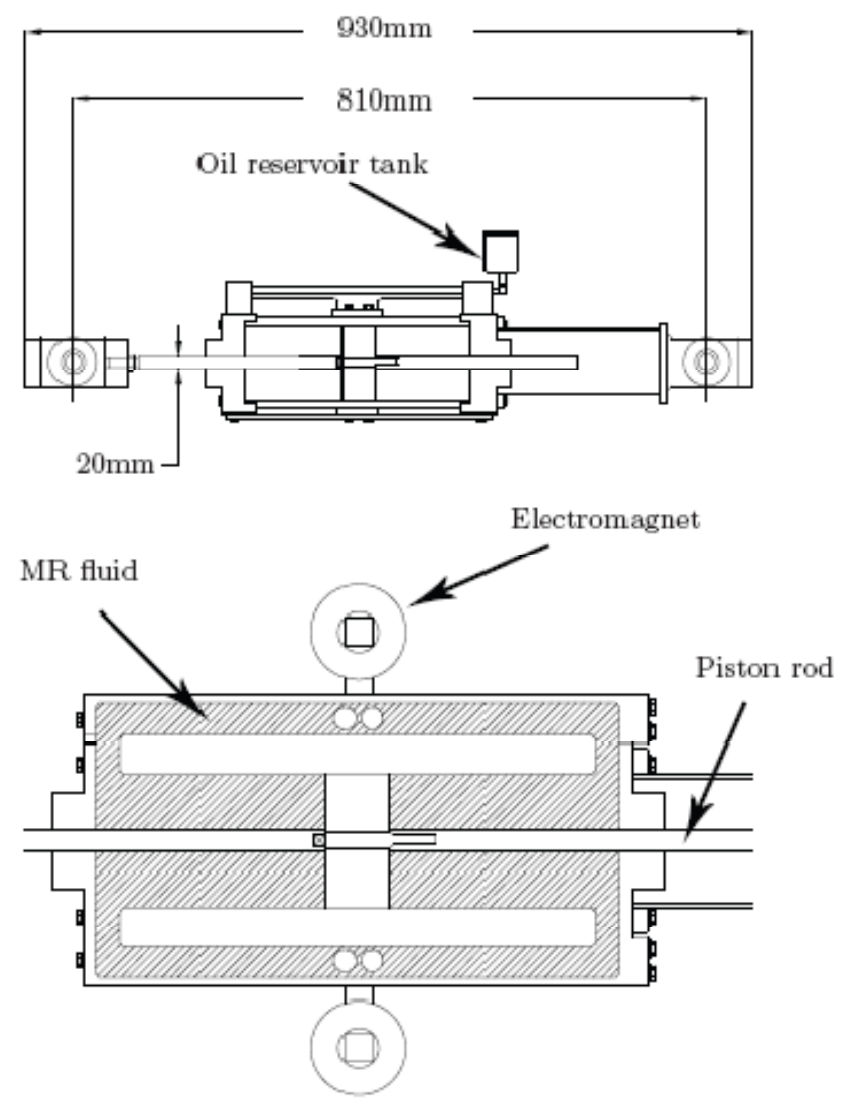

Figure 3. MR damper detail

The MR damper model in equations (3)-(4), which is based on the normalized Bouc-Wen model in equations (1)-(2), was obtained from a model validation using both constant and varying current along with a varying displacement signal (Rodríguez et al., 2009). This normalized Bouc-Wen model depicts its current dependent parameters in equations (6)-(8):

$$
\begin{gathered}
F_{M R}(t)=\left[\kappa_{\dot{x}, a} i(t)+\kappa_{\dot{x}, b}\right] \dot{x}(t)+\left[\kappa_{w, a} i^{2}(t)+\kappa_{w, b} i(t)+\kappa_{w, c}\right] w(t) \\
\dot{w}(t)=\left[\rho_{a} i^{2}(t)+\rho_{b} i(t)+\rho_{c}\right]\left(\dot{x}(t)-\sigma|\dot{x}(t)||w(t)|^{n-1} w(t)+(\sigma-1) \dot{x}(t)|w(t)|^{n}\right) \\
w(0)=\frac{F(0)-\left[\kappa_{\dot{x}, a} i(0)+\kappa_{\dot{x}, b}\right] \dot{x}(0)}{\left[\kappa_{w, a} i^{2}(0)+\kappa_{w, b} i(0)+\kappa_{w, c}\right]} \\
\kappa_{\dot{x}}(i)=\kappa_{\dot{x}, a} i+\kappa_{\dot{x}, b}=328.47 i+35.14 \mathrm{~N} / \mathrm{mm}
\end{gathered}
$$




$$
\begin{gathered}
\kappa_{w}(i)=\kappa_{w, a} i^{2}+\kappa_{w, b} i+\kappa_{w, c}=-136910 i^{2}+62530 i+600 \mathrm{~N} \\
\rho(i)=\rho_{a} i^{2}+\rho_{b} i+\rho_{c}=12.25 i^{2}-3.8 i+0.93 \mathrm{~mm}^{-1}
\end{gathered}
$$

The parameters $n$ and $\sigma$ barely show dependence on the current; therefore, constant average values are considered, $n=1.63$ and $\sigma=1.85$.

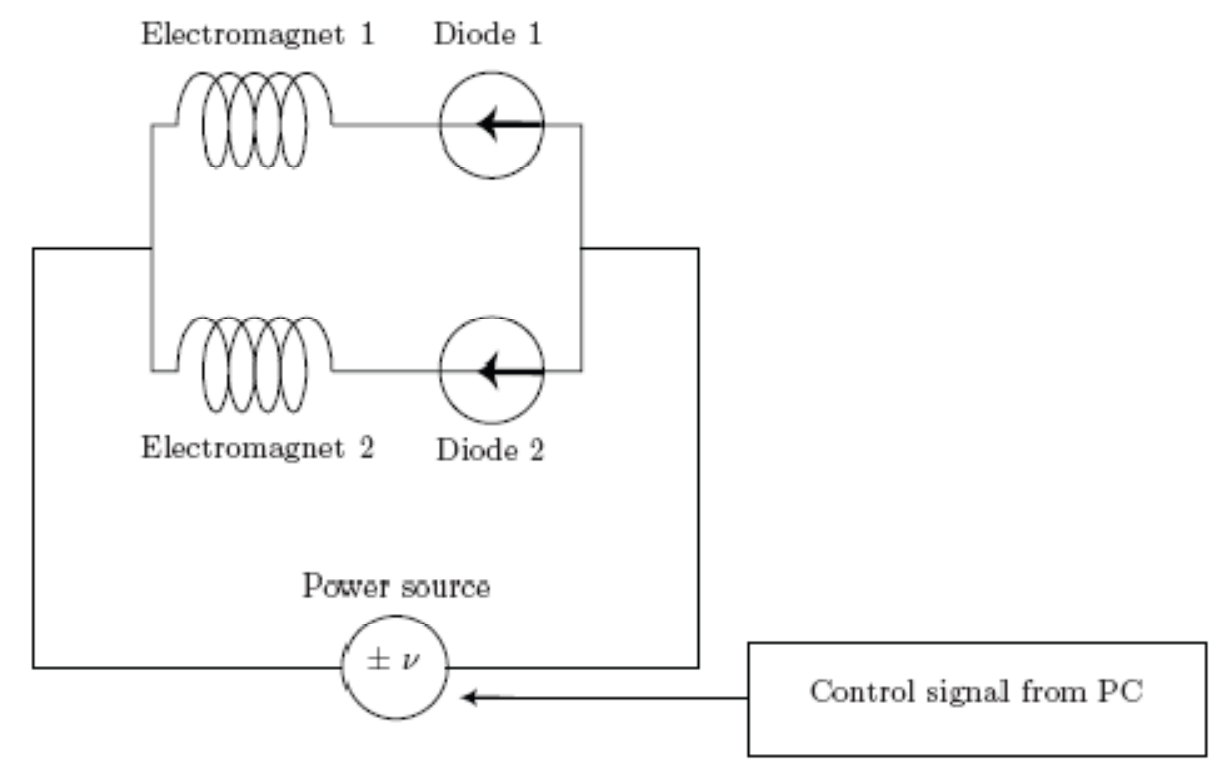

Figure 4. MR damper electric circuit detail

\section{Scalability}

The MR fluid damper that was experimentally identified has a nominal force of $20 \mathrm{kN}$. However, in order to attain the requirements of the benchmark base-isolated building, these MR dampers have to have a larger nominal force. Recently, Fujitani et al. (2003) developed a set of 40-t magnetorheological fluid dampers to be installed in a residential building in Japan along with laminated rubber bearings, lead dampers, and oil dampers to provide the best seismic protection. It is the first smart base-isolated building using MR dampers technology instead of variable-orifice dampers, like Keio University School of Science and Technology in Japan. The approach taken in this paper is to scale the $20 \mathrm{kN}$ experimentally identified large-scale MR fluid damper to a $400 \mathrm{kN}$ MR fluid damper and also, to a $2000 \mathrm{kN}$ one, which is close to the one employed in the sample benchmark problem (Narasimhan et al., 2006). A similar approach is used in (Yoshida and Dyke, 2004), scaling a $30 \mathrm{~N}$ shear-mode MR damper model to a 1000 $\mathrm{kN}$ ideal MR damper. The nominal force comparison is done to correlate the efficiency of the semi-active control law using the $2000 \mathrm{kN}$ MR fluid damper with other references in the benchmark base-isolated building (Narasimhan et al., 2006). Moreover, the same results are compared with a manufacturable 400 $\mathrm{kN}$ MR fluid damper in order to show that the proposed model is a good candidate for a real base-isolated building employing large-scale MR fluid dampers.

Regarding the scalability (Carlson and Spencer, 1996), the static behavior of the MR damper does not have the dependence on size-dependent numbers such as the Nusselt number (as happened with electromagnetic actuators). Hence, as long as the static behavior is concerned, the scalability criterium 
applies for the usual industrial range of dimensions. However, when current is applied, the MR damper does have current-dependence on the parameters $\kappa_{\dot{\chi}}(i), \kappa_{w}(i)$, and $\rho(i)$ shown in equations (6), (7), and (8), respectively.

Although some magnetic (demagnetization, saturation, and magnetization hysteresis) and mechanical (friction and mechanical stress) effects are important in magnetorheological dampers, this work assumes that the current is the quantity that limits the available force. Although there are losses caused by the magnetic hysteresis, eddy currents, and friction, the resistive losses are dominant in the considered damper operation, and hence, only such resistive losses are considered. The force provided by these actuators can be analyzed with dimensional analysis using the Buckingham's Pi theorem (Buckingham, 1914; Harris and Sabnis, 1999), the quantities involved are shown in the Table II. The force--current--Young's modulus--acceleration system is used, and the scaled parameters are shown as follows:

$$
\begin{array}{cc}
\lambda_{F_{400 k \mathrm{~N}}}=20 ; & \lambda_{i_{400 \mathrm{KN}}}=20 \\
\lambda_{F_{2000 \mathrm{kN}}}=100 ; & \lambda_{i_{2000 \mathrm{kN}}}=100
\end{array}
$$

The geometrical parameters of the MR fluid damper vary differently depending on the manufacturers (Gavin et al., 2001); therefore, we will not focus on the design details in this paper. The parameters $\kappa_{\dot{\chi}}(i)$ $\kappa_{w}(i)$, and $\rho(i)$ in equations (6), (7), and (8), respectively, can be scalable following Table II. The $400 \mathrm{kN}$ scaled up MR fluid damper model may be rewritten as follows:

$$
\begin{gathered}
\kappa_{\dot{x}}(i)=1469 i+157.2 \mathrm{kN} / \mathrm{m} \\
\kappa_{w}(i)=-2738.2 i^{2}+1250.6 i+12 \mathrm{kN} \\
\rho(i)=2739.2 i^{2}-849.7 i+207.95 \mathrm{~m}^{-1}
\end{gathered}
$$

Table II. Scaling factors

\begin{tabular}{llll}
\hline \multicolumn{1}{c}{ Parameters } & Scaling factor & $20: 1$ Target model & $100: 1$ Target model \\
\hline Force & $l_{r}$ & $20 / 1$ & $100 / 1$ \\
Current & $l_{r}$ & $20 / 1$ & $100 / 1$ \\
Length & $\sqrt{l_{r}}$ & $\sqrt{20} / 1$ & $\sqrt{100} / 1$ \\
Velocity & $\sqrt{l_{r}}$ & $\sqrt{20} / 1$ & $\sqrt{100} / 1$ \\
Acceleration & 1 & 1 & 1 \\
Young’s modulus & 1 & 1 & 1 \\
Time & $\sqrt{l_{r}}$ & $\sqrt{20} / 1$ & $\sqrt{100} / 1$ \\
Mass & $\left(l_{r}\right)^{2}$ & $\left(20^{2}\right) / 1$ & $\left(100^{2}\right) / 1$ \\
\hline
\end{tabular}


And the $2000 \mathrm{kN}$ scaled up MR fluid damper model may be also rewritten as follows:

$$
\begin{gathered}
\kappa_{\dot{\chi}}(i)=3284.7 i+351.4 \mathrm{kN} / \mathrm{m} \\
\kappa_{w}(i)=-13691 i^{2}+625.3 i+60 \mathrm{kN} \\
\rho(i)=1225 i^{2}-380 i+93 \mathrm{~m}^{-1}
\end{gathered}
$$

The parameters $n$ and $\sigma$ are dimensionless; therefore, their values are $n=1.63$ and $\sigma=1.85$.

Table III. Scaled-up 400 kN MR fluid damper

\begin{tabular}{lll}
\hline \multicolumn{1}{c}{ Parameters } & Original model & Target manufacturable model \\
\hline Maximum force (nominal) & $20 \mathrm{kN}$ & $400 \mathrm{kN}$ \\
Stroke & $\pm 100 \mathrm{~mm}$ & $\pm 447.21 \mathrm{~mm}$ \\
Cylinder bore & $95 \mathrm{~mm}$ & $175 \mathrm{~mm}$ \\
Orifice size & $2 \mathrm{~mm} \times 20 \mathrm{~mm}$ & $3 \mathrm{~mm} \times 90 \mathrm{~mm}$ \\
Coil & 2 with 3800 turns & 5 layers $\times 4$ groups \\
Inductance & $1.5 \mathrm{H}$ & $60 \mathrm{mH}$ (for each coil group) \\
Coil resistance & $60 \Omega$ & $20 \Omega$ (for each coil group) \\
Maximum current & $0.3 \mathrm{~A}$ & $6 \mathrm{~A}$ \\
\hline
\end{tabular}

\section{Force-derivative Feedback Semi-active Control Algorithm Development}

There exists a wide range of control algorithms that are applied to base-isolated buildings: clipped-optimal control (Dyke et al., 1996; Jung et al., 2006; Yoshida and Dyke, 2004); maximum energy dissipation algorithms (Luo et al., 2001); and modulated homogeneous friction algorithms, among others. Each of these controllers is able to reduce the structural response to some degree. From a structural point of view, a reasonable controller has to reduce the base displacement while decreases or slightly increases the accelerations. $\mathrm{Li}$ and Ou (2006) showed that the active control forces in base-isolated structures have damping characteristics. In this study, an active force-derivative feedback controller will be applied in a semi-active way to the base-isolated benchmark building (Narasimhan et al., 2006). The control forces will be applied at the base through manipulation of the command current at the MR dampers.

\section{System Description}

The system description considers a nonlinear base-isolated building structure as shown in Figure 5. More precisely, the control design is based on a dynamic model composed of two coupled subsystems, namely, the main structure or superstructure $\left(S_{r}\right)$ and the base isolation $\left(S_{c}\right)$ (Naeim and Kelly, 1999):

$$
S_{r}: \mathrm{M} \ddot{\mathrm{x}}=-\mathrm{MJ} \ddot{x}_{g}-\mathrm{C} \dot{\mathrm{r}}-\mathrm{Kr}
$$




$$
S_{c}: m \ddot{x}+c \dot{x}+k x=c_{1} \dot{r_{1}}+k_{1} r_{1}-m \ddot{x}_{g}-F_{M R}+u
$$

where $\ddot{x}_{g}$ is the absolute ground acceleration, $\mathbf{x}=\left[x_{1}, x_{2}, \ldots, x_{8}\right]^{T} \in \mathbb{R}^{8}$ represents the horizontal displacements of each floor with respect to the ground. The mass, damping and stiffness of the $i$ th storey is denoted by $m_{i}, c_{i}$ and $k_{i}$, respectively, $\mathbf{r}=\left[r_{1}, \ldots, r_{8}\right]^{T} \in \mathbb{R}^{8}$, represents the horizontal displacements of the $i$ th floor relative to the $(i-1)$-th floor. The base isolation is described as a single degree of freedom with horizontal displacement $x$. It is assumed to exhibit a linear behavior characterized by mass, damping and stiffness $m, c$ and $k$, respectively, plus a nonlinear behavior represented by a hysteretic restoring force $F_{M R}$. The matrices $\mathrm{M}, \mathrm{C}, \mathrm{K}$ and $\mathrm{J}$ of the structure have the following form:

$$
\begin{gathered}
\mathbf{M}=\operatorname{diag}\left(m_{1}, m_{2}, \ldots, m_{8}\right) \in \mathbb{R}^{8} \\
\mathrm{~J}=[1, \ldots, 1]^{T} \in \mathbb{R}^{8} \\
\mathbf{C}=\left(c_{i j}\right) \in \mathbb{R}^{8 \times 8}, c_{i j}=\left\{\begin{aligned}
c_{i}, & i=j \\
-c_{i+1}, & j-i=1 \\
0, & \text { otherwise }
\end{aligned}\right. \\
\mathbf{K}=\left(k_{i j}\right) \in \mathbb{R}^{8 \times 8}, k_{i j}=\left\{\begin{aligned}
k_{i}, & i=j \\
-k_{i+1}, & j-i=1 \\
0, & \text { otherwise }
\end{aligned}\right.
\end{gathered}
$$

Finally, $u$ is the control force supplied by an appropriate actuator.

The model in (15)-(16) is used to design an appropriate control law. The applicability and efficiency of the proposed controller will be then shown using a more realistic and complex model through the benchmark presented in Section 5.

The equation of motion of the base (16) can be written in the form

$$
S_{c}: m \ddot{x}+c \dot{x}+k x=\underbrace{c_{1}\left(\dot{x}_{1}-\dot{x}\right)+k_{1}\left(x_{1}\right)}_{\delta\left[x, \dot{x}, x_{1}, \dot{x}_{1}\right]}-\underbrace{F_{M R}-m \ddot{x}_{g}}_{\Delta(t)}+u
$$

It is well accepted that the movement of the superstructure $S_{r}$ is very close to the one of a rigid body due to the base isolation (Pozo et al., 2008). Then it is reasonable to assume that the motion of the first floor relative to the base will be very small. Therefore, it is also reasonable that the interaction force $\delta\left[x, \dot{x}, x_{1}, \dot{x}_{1}\right]$ will be small in comparison with the rest of the forces acting on the base (Luo et al., 2001). Consequently, the following simplified equation of motion of the base can be used in the subsequent controller design:

$$
\tilde{S}_{c}: m \ddot{x}+c \dot{x}+k x=-F_{M R}-m \ddot{x}_{g}+u
$$

\section{Force-derivative feedback controller}

Force-feedback controllers have received great attention in the active cable control of cable-stayed bridges (Bossens and Preumont, 2001), where the concept of integral force feedback is introduced, offering a sufficient increase of structure damping by suitable sensor-actuator-pairs integrated between the stay-cables and the bridge deck. The static loads are compensated by hydraulic accumulators without permanent power supply. Moreover, force-feedback controllers have been seen in active vibration isolation (Benassi et al., 2004; Preumont et al., 2002), where it is shown that the force feedback implementation benefits from alternating poles and zeros which allows a control law with guaranteed stability, making it very attractive when the payload to be isolated from the disturbance source is very flexible, such as in large space structures. At the same time, other applications have been seen in 
piezoelectric actuators for vibration control of civil structures used (decentralized) integral force feedback control (Songa et al., 2006), vehicle vibration control using MR dampers (Wang et al., 2003), and hybrid structural simulation (Ahmadizadeh et al., 2008) and (Yoshida and Dyke, 2004).

Assuming that the earthquake disturbance is unknown but bounded, the following force-derivative feedback controller is proposed:

$$
u=-\zeta \dot{F}_{M R},
$$

where $\zeta$ is a positive real number. From an active control point of view, the force which has to be supplied by the actuator is based on the measured force which is currently applied by the MR damper.

More precisely, the following assumption is stated for system (17):

Assumption 1. The earthquake disturbance $-m \ddot{x}_{g}(t)$ is unknown but bounded; i.e., there exists a known constant $G$ such that $\left|\ddot{x}_{g}(t)\right| \leq G, \forall t \geq 0$.

Moreover, Theorem 1 in (Ikhouane et al., 2005) guarantees the existence of a computable upper bound $\rho_{w}$ on the internal dynamic variable $w(t)$, i.e., $|w(t)| \leq \rho_{w}, \forall t \geq 0$, independently on the boundedness of $x(t)$.

The following theorem states the bounded-input bounded-output stability of the proposed controller.

Theorem 1. Consider the nonlinear system in equation (17) and the force-derivative feedback control law

$$
u=-\zeta F_{M R}^{\cdot},
$$

under the assumption of the boundedness of the earthquake disturbance. Then, the closed-loop system in equations (17) and (19) is bounded-input bounded-output stable.

Proof. This proof is based on the boundedness of the earthquake disturbance $-m \ddot{x}_{g}$.

The closed-loop system in equations (17) and (19) yields

$$
m \ddot{x}+c \dot{x}+k x=-\underbrace{\left(\kappa_{\dot{x}} \dot{x}+\kappa_{w} w\right)}_{F_{M R}}-m \ddot{x}_{g}-\zeta \underbrace{\left(\kappa_{\dot{x}} \ddot{x}+\kappa_{w} \dot{w}\right)}_{F_{M R}} .
$$

Applying the Laplace transform to the equation of motion of the base, we obtain

$$
\left[\left(m+\zeta \kappa_{\dot{x}}\right) s^{2}+\left(c+\kappa_{\dot{x}}\right) s+k\right] x(s)=-m \ddot{x_{g}}(s)-\left[\zeta \kappa_{w} s+\kappa_{w}\right] w(s),
$$

where $x(s), w(s)$ and $\ddot{x_{g}}(s)$ are the Laplace transform of the signals $x(t), w(t)$ and $\ddot{x}_{g}(t)$, respectively. The direct transfer function between the ground motion $\ddot{x_{g}}$, the hysteretic variable $w$, and the controlled base displacement $x$ is

$$
\begin{gathered}
x(s)=\frac{-m}{\left(m+\zeta \kappa_{\dot{x}}\right) s^{2}+\left(c+\kappa_{\dot{x}}\right) s+k} \ddot{x}_{g}(s)-\frac{\zeta \kappa_{w} s+\kappa_{w}}{\left(m+\zeta \kappa_{\dot{x}}\right) s^{2}+\left(c+\kappa_{\dot{x}}\right) s+k} w(s) \\
x(s)=T_{g}(s) \ddot{x}_{g}(s)+T_{w}(s) w(s)
\end{gathered}
$$

It can be shown, using the Nyquist stability criterion, that the transfer functions $T_{g}(s)$ and $T_{w}(s)$ are stable. Therefore, the boundedness of the input signals $\ddot{x}_{g}(t)$ and $w(t)$ guarantees the boundedness of the output signal $x(t)$, that is, the base displacement.

The inverse model

The inverse model will provide a suitable tool to compute the command current of MR dampers analytically. Consider again the normalized form of the Bouc--Wen model for MR dampers:

$$
F_{M R}(t)=\left[\kappa_{\dot{x}, a} i(t)+\kappa_{\dot{x}, b}\right] \dot{x}(t)+\left[\kappa_{w, a} i^{2}(t)+\kappa_{w, b} i(t)+\kappa_{w, c}\right] w(t),
$$


where $F_{M R}(t)$ is the output force of the MR damper. The inverse model (see Figure 6), that is, the computation of the current $i$ as a function of the velocity and force, is based on the following simplification:

(a) the internal dynamic variable $w(t)$, which is unmeasurable, is replaced by the sign of the velocity:

$$
w(t)=\operatorname{sgn}(\dot{x}) \in\{-1,1\} .
$$

We remark that, in the normalized version of the Bouc-Wen model, the value of this internal dynamic variable lies within the range $[-1,1]$. The feasibility of this simplification is illustrated in Figure 7.

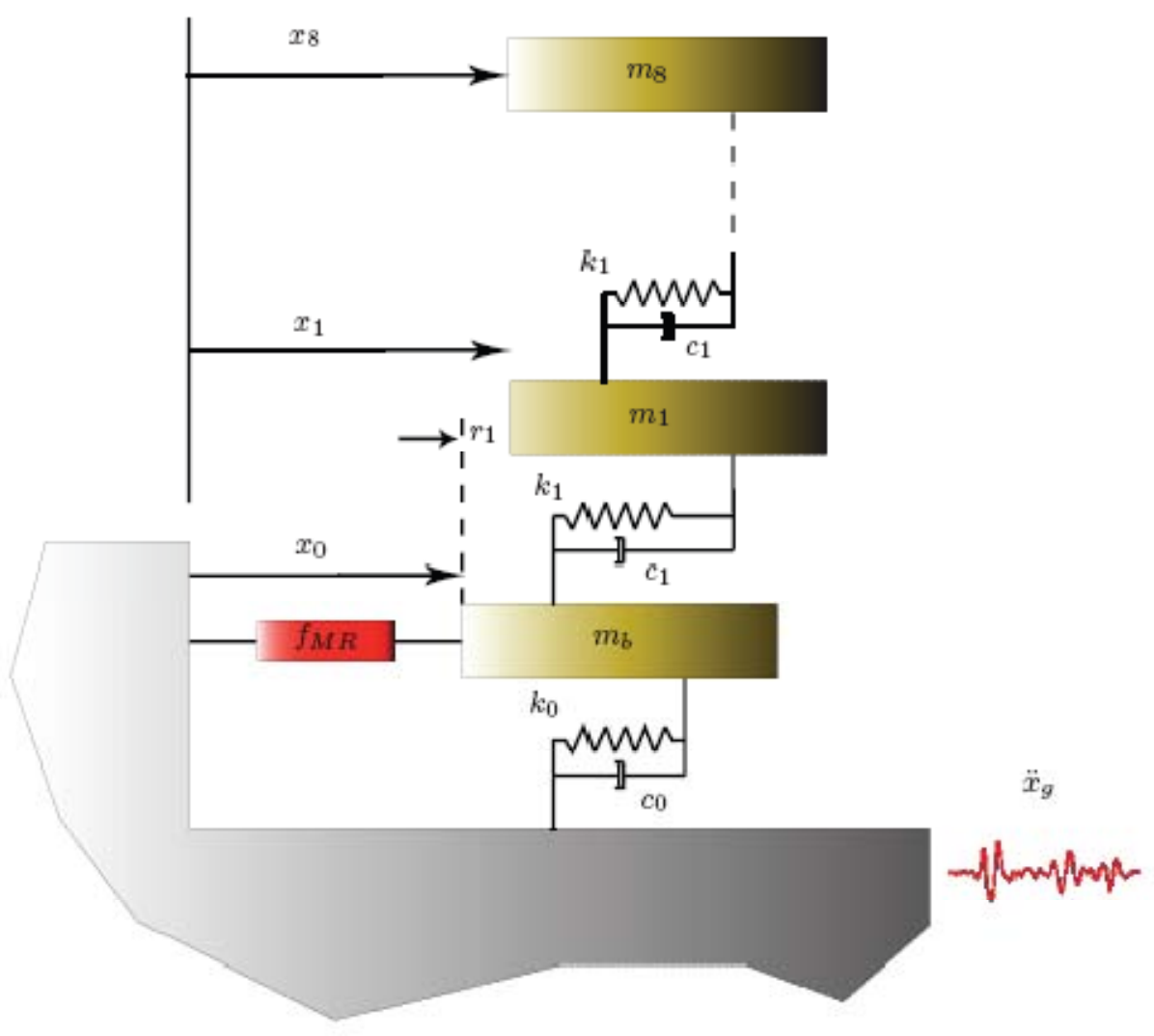

Figure 5. Two degree-of-freedom (2DOF) model.

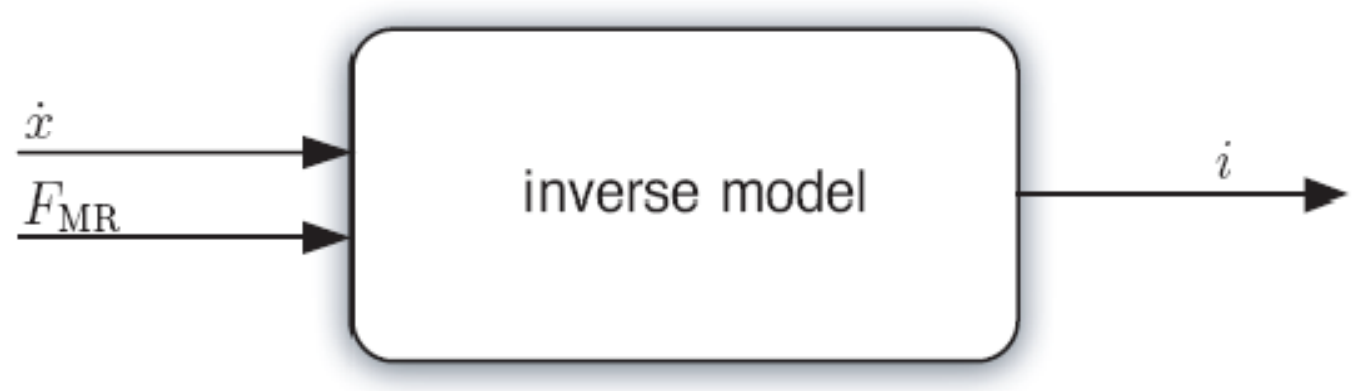

Figure 6. Input-output variables of the inverse model. 
As a result of this simplification, the MR damper model is

$$
\begin{gathered}
F_{M R}(t)=\left[\kappa_{\dot{x}, a} i(t)+\kappa_{\dot{x}, b}\right] \dot{x}(t)+\left[\kappa_{w, a} i^{2}(t)+\kappa_{w, b} i(t)+\kappa_{w, c}\right] \operatorname{sgn}(\dot{x}) \\
F_{M R}(t)=\left[\kappa_{w, a} \operatorname{sgn}(\dot{x})\right] i^{2}(t)+\left[\kappa_{\dot{x}, a} \dot{x}(t)+\kappa_{w, b} \operatorname{sgn}(\dot{x})\right] i(t)+\left[\kappa_{\dot{x}, b} \dot{x}(t)+\kappa_{w, c} \operatorname{sgn}(\dot{x})\right]
\end{gathered}
$$

The current $i(t)$ can be found by solving the quadratic equation

$$
\underbrace{\kappa_{w, a} \operatorname{sgn}(\dot{x})}_{a_{2}} i^{2}(t)+\underbrace{\left[\kappa_{\dot{x}, a} \dot{x}(t)+\kappa_{w, b} \operatorname{sgn}(\dot{x})\right]}_{a_{1}} i(t)+\underbrace{\kappa_{\dot{x}, b} \dot{x}(t)+\kappa_{w, c} \operatorname{sgn}(\dot{x})-F_{M R}(t)}_{a_{0}}=0 .
$$

Thereby, the final form of the inverse model will be:

$$
\begin{aligned}
& i\left(\dot{x}, F_{M R}\right)=\frac{-a_{1} \pm \sqrt{a_{1}^{2}-4 a_{2} a_{0}}}{2 a_{2}} \\
& =\frac{-\kappa_{\dot{x}, a} \dot{x}(t)-\kappa_{w, b} \operatorname{sgn}(\dot{x})}{2 \kappa_{w, a} \operatorname{sgn}(\dot{x})} \\
& \pm \frac{\sqrt{4 \kappa_{w, a} \operatorname{sgn}(\dot{x}) F_{M R}(t)+\kappa_{\dot{x}, a}^{2} \dot{x}(t)^{2}+\left[2 \kappa_{\dot{x}, a} \kappa_{w, b}-4 \kappa_{w, a} \kappa_{\dot{x}, b}\right]|\dot{x}(t)|+\kappa_{w, b}^{2}-4 \kappa_{w, a} \kappa_{w, c}}}{2 \kappa_{w, a} \operatorname{sgn}(\dot{x})}
\end{aligned}
$$

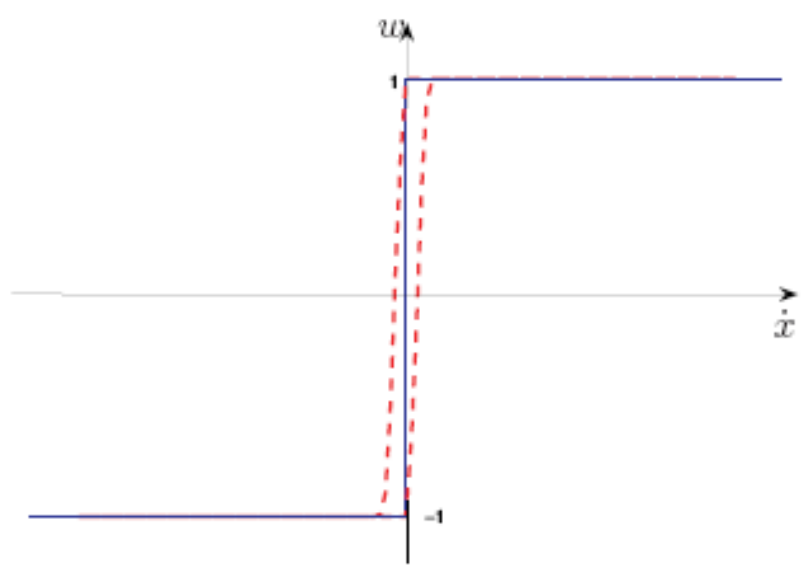

Figure 7. The internal dynamic variable $w(t)$ is approximated by the sign of the velocity.

The selection of the command current $i$

It is well known that the force generated by the MR damper cannot be commanded; only the voltage $v$ or the current $i$ applied to the MR damper can be directly changed (Dyke and Spencer, 1996). In the clipped-optimal control algorithm (Dyke and Spencer, 1996), the command voltage takes the values zero or the maximum, according to

$$
v=V_{\text {max }} H\left\{\left(f_{d}-F_{M R}\right) F_{M R}\right\},
$$

where $V_{\max }$ is the maximum voltage to the current driver associated with saturation of the magnetic field in the MR damper, $H(\cdot)$ is the Heaviside step function, $f_{d}$ is the desired control force and $F_{M R}$ is the measured force of the MR damper. In some situations, when the dominant frequencies of the system 
under control are low, large changes in the forces applied to the structure may result in high local acceleration (Yoshida and Dyke, 2004). In this sense, a modification to the original clipped-optimal control algorithm in which the control voltage can be any value between zero and a $V_{\text {max }}$, was proposed in (Yoshida and Dyke, 2004). A similar approach can be found in (Gu and Oyadiji, 2004), where a force-feedback control scheme is employed to overcome the difficulty of commanding the MR damper to produce an arbitrary force. In this paper we consider the same idea of changing the voltage but changing the current according to the inverse model in equation (20). More precisely, to induce the MR damper to generate approximately the desired control force $f_{d}$, the algorithm for selecting the command signal can be concisely stated as

$i\left(\dot{x}, F_{M R}\right)=\frac{-\kappa_{\dot{x}, a} \dot{x}(t)-\kappa_{w, b} \operatorname{sgn}(\dot{x})}{2 \kappa_{w, a} \operatorname{sgn}(\dot{x})}$

$\pm \frac{\sqrt{4 \kappa_{w, a} \operatorname{sgn}(\dot{x}) f_{d}(t)+\kappa_{\dot{x}, a}^{2} \dot{x}(t)^{2}+\left[2 \kappa_{\dot{x}, a} \kappa_{w, b}-4 \kappa_{w, a} \kappa_{\dot{x}, b}\right]|\dot{x}(t)|+\kappa_{w, b}^{2}-4 \kappa_{w, a} \kappa_{w, c}}}{2 \kappa_{w, a} \operatorname{sgn}(\dot{x})}$

where $f_{d}$ is computed according to

$$
f_{d}=\dot{F}_{M R} .
$$

Both equations (21)-(22) define a semi-active controller. Figure 8 illustrates the corresponding closed-loop system.

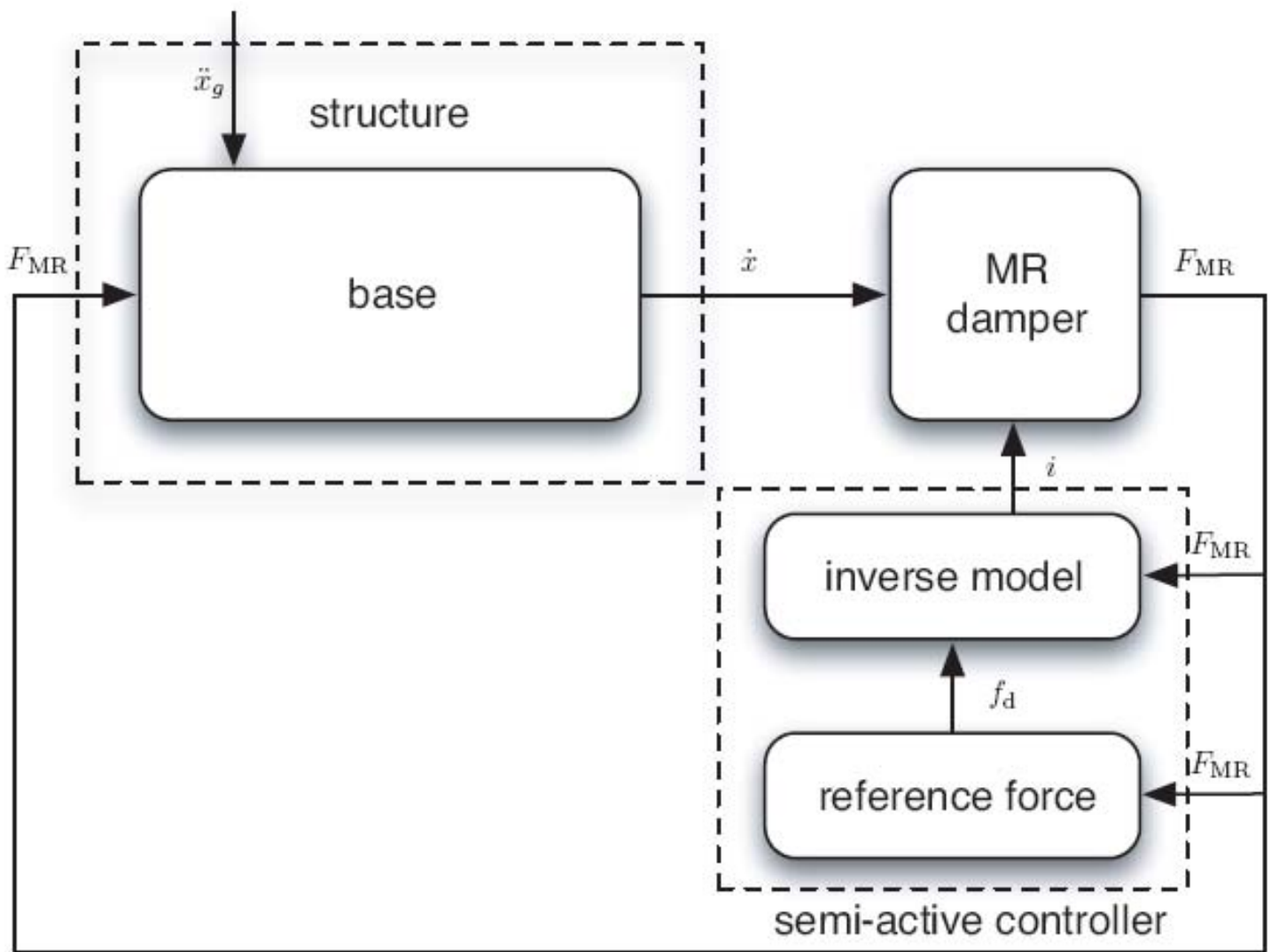

Figure 8. Block diagram of the semi-active control system for a single MR damper. 


\section{Hierarchical control scheme}

The number $n_{M R}$ of MR dampers and their locations are the same as the sample paper (Narasimhan et al., 2006) for the $2000 \mathrm{kN}$ MR damper. However, the number and location are increased by a factor of 5 for the $400 \mathrm{kN}$ MR fluid damper. At each location, there are two controllers -one in the $x$ - and the other in the $y$-direction. These actuators are used to apply the damping control forces to the base of the structure.

This section proposes a overall strategy to implement the previous control loop no through a single damper but by means of a set of several MR dampers.

The final goal of the semi-active control scheme is that the total damping force generated by the whole set of MR dampers closely follows the desired control force $f_{d}$. With this aim, we propose a hierarchical semi-active control strategy as illustrated in Figure 9. With this scheme, we have to decide whether it is necessary to apply current to the dampers, to which dampers, and the magnitude of the current. More precisely, this procedure can be summarized in the following steps to be implemented real-time at each sampling instant:

Step 1. Compute the desired control force $f_{d}$, according to the control law in equation (22).

Step 2. If the magnitude of the total damping force generated by the MR dampers, $f_{M R}:=$ $\sum_{j=1}^{n_{M R}} f_{M R}^{j}$, is smaller than the magnitude of the desired control force $f_{d}$ and the two forces have the same sign, that is, if the following expression holds

$$
\left(f_{d}-f_{M R}\right) f_{M R}>0 \text {, }
$$

it means that the MR dampers need to apply more damping force and then we go to step 3. Otherwise, the current applied to each damper is set to $i_{j}=0, j=1, \ldots, n_{M R}$, and we leave them work passively.

Step 3. Compute the number of dampers that are applying force in the same direction that the desired control force. In this sense, we define the following set

Let $N$ be the cardinal of this set.

$$
L=\left\{j \in\left\{1, \ldots, n_{M R}\right\} \mid \operatorname{sgn}\left(f_{M R}^{j}\right) \operatorname{sgn}\left(f_{d}\right)>0\right\} .
$$

Step 4. Compute the corresponding command current. Each of the $N$ dampers has to offer a part of the control force equal to $\frac{f_{d}}{N}$. Based on this desired value, the corresponding command current that has to be applied to each damper will be calculated according to equation (21). Let $i_{\alpha}$ and $i_{\beta}$ be the two roots of the equation

$$
\begin{aligned}
i_{\alpha}, i_{\beta} & =\frac{-\kappa_{\dot{x}, a} \dot{x}(t)-\kappa_{w, b} \operatorname{sgn}(\dot{x})}{2 \kappa_{w, a} \operatorname{sgn}(\dot{x})} \\
& \pm \frac{\sqrt{4 \kappa_{w, a} \operatorname{sgn}(\dot{x}) \frac{f_{d}(t)}{N}+\kappa_{\dot{x}, a}^{2} \dot{x}(t)^{2}+\left[2 \kappa_{\dot{x}, a} \kappa_{w, b}-4 \kappa_{w, a} \kappa_{\dot{x}, b}\right]|\dot{x}(t)|+\kappa_{w, b}^{2}-4 \kappa_{w, a} \kappa_{w, c}}}{2 \kappa_{w, a} \operatorname{sgn}(\dot{x})}
\end{aligned}
$$

and let $\left[0, i_{\text {max }}\right]$ be the range of admissible current. The applied current $i_{j}, j=1, \ldots, n_{M R}$ will finally be 


$$
i_{j}=\left\{\begin{aligned}
\max \left\{i_{\alpha}, i_{\beta}\right\}, & i_{\alpha}, i_{\beta} \in\left[0, i_{\text {max }}\right], j \in L \\
\min \left\{i_{\alpha}, i_{\beta}\right\}, & \min \left\{i_{\alpha}, i_{\beta}\right\} \in\left[0, i_{\text {max }}\right], \max \left\{i_{\alpha}, i_{\beta}\right\} \notin\left[0, i_{\text {max }}\right], j \in L \\
i_{\text {max }}, & i_{\alpha}, i_{\beta}>0, \min \left\{i_{\alpha}, i_{\beta}\right\} \notin\left[0, i_{\text {max }}\right], j \in L \\
\max \left\{i_{\alpha}, i_{\beta}\right\}, & \min \left\{i_{\alpha}, i_{\beta}\right\}<0, \max \left\{i_{\alpha}, i_{\beta}\right\} \in\left[0, i_{\text {max }}\right], j \in L \\
i_{\text {max }}, & \min \left\{i_{\alpha}, i_{\beta}\right\}<0, \max \left\{i_{\alpha}, i_{\beta}\right\} \geq i_{\text {max }}, j \in L \\
0, & \max \left\{i_{\alpha}, i_{\beta}\right\}<0, j \in L \\
\Re\left(i_{\alpha}\right), & i_{\alpha} \in \mathbb{C} \backslash \mathbb{R}, 0 \leq \Re\left(i_{\alpha}\right) \leq i_{\text {max }}, j \in L \\
0, & i_{\alpha} \in \mathbb{C} \backslash \mathbb{R}, \mathfrak{R}\left(i_{\alpha}\right)<0, j \in L \\
i_{\text {max }}, & i_{\alpha} \in \mathbb{C} \backslash \mathbb{R}, \mathfrak{R}\left(i_{\alpha}\right)>i_{\text {max }}, j \in L \\
0, & j \notin L
\end{aligned}\right.
$$

In the implementation of this formula, the values are truncated between zero and $i_{\text {max }}$ when the current does not belong to the range of admissible values. When the roots are complex conjugates, we just consider the real part, and then we apply the same truncation.

This process helps the total damping force generated by the MR dampers become more closer to the desired control force, $f_{d}$.

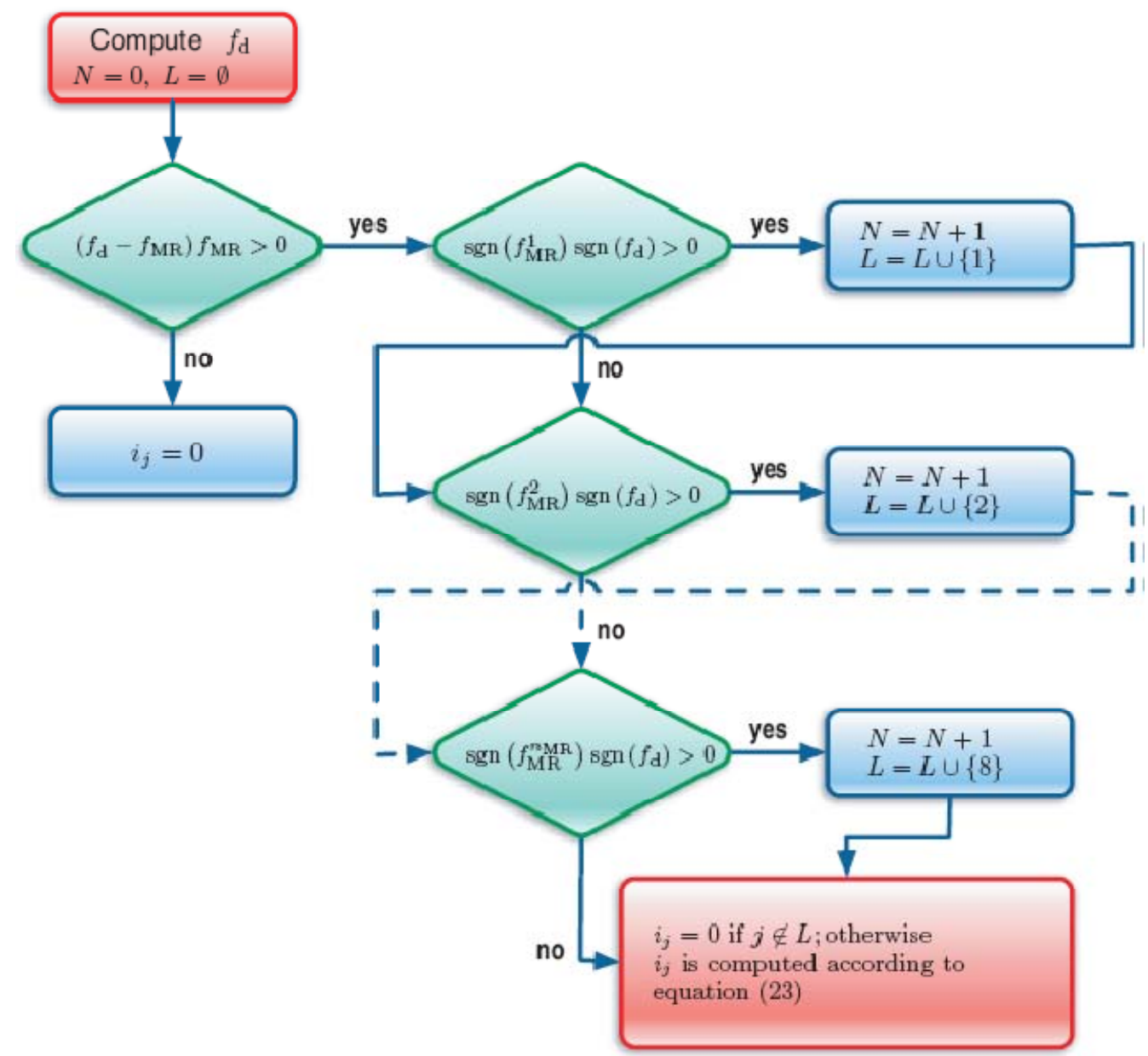

Figure 9. Hierarchical semi-active control: flow diagram. 


\section{Smart Base-Isolated Benchmark Building}

The smart base-isolated benchmark building (Narasimhan et al., 2006) is employed as an interesting and more realistic example to further investigate the effectiveness of the proposed design approach. This benchmark problem is recognized by the American Society of Civil Engineers (ASCE) Structural Control Committee as a state-of-the-art model developed to provide a computational platform for numerical experiments of seismic control attenuation (Ohtori et al., 2004; Spencer and Nagarajaiah, 2003).

The benchmark base-isolated building developed by Narasimhan et al. (2006) is an eight-storey frame building with steel-braces, $82.4 \mathrm{~m}$ long and $54.3 \mathrm{~m}$ wide, similar to existing building in Los Angeles, California (see Figure 10). The superstructure has eight stories and is considered to be a linear elastic system with lateral-torsional behavior. In this paper, linear elastomeric bearings have been used to isolate the building. Totally 92 isolators are connected between drop panels under the column locations and the footings in this model, as shown in Figure 11. The superstructure and the isolation system are modeled with three master degree-of-freedoms (DOFs). As a result, the entire structure is condensed to have a total of 27 DOFs. The first three periods of the fixed-base model in three directions are $0.78,0.27,0.15$ seconds in north-south direction, $0.89,0.28,0.15$ seconds in east-west direction and $0.66,0.21,0.12$ seconds in rotation.
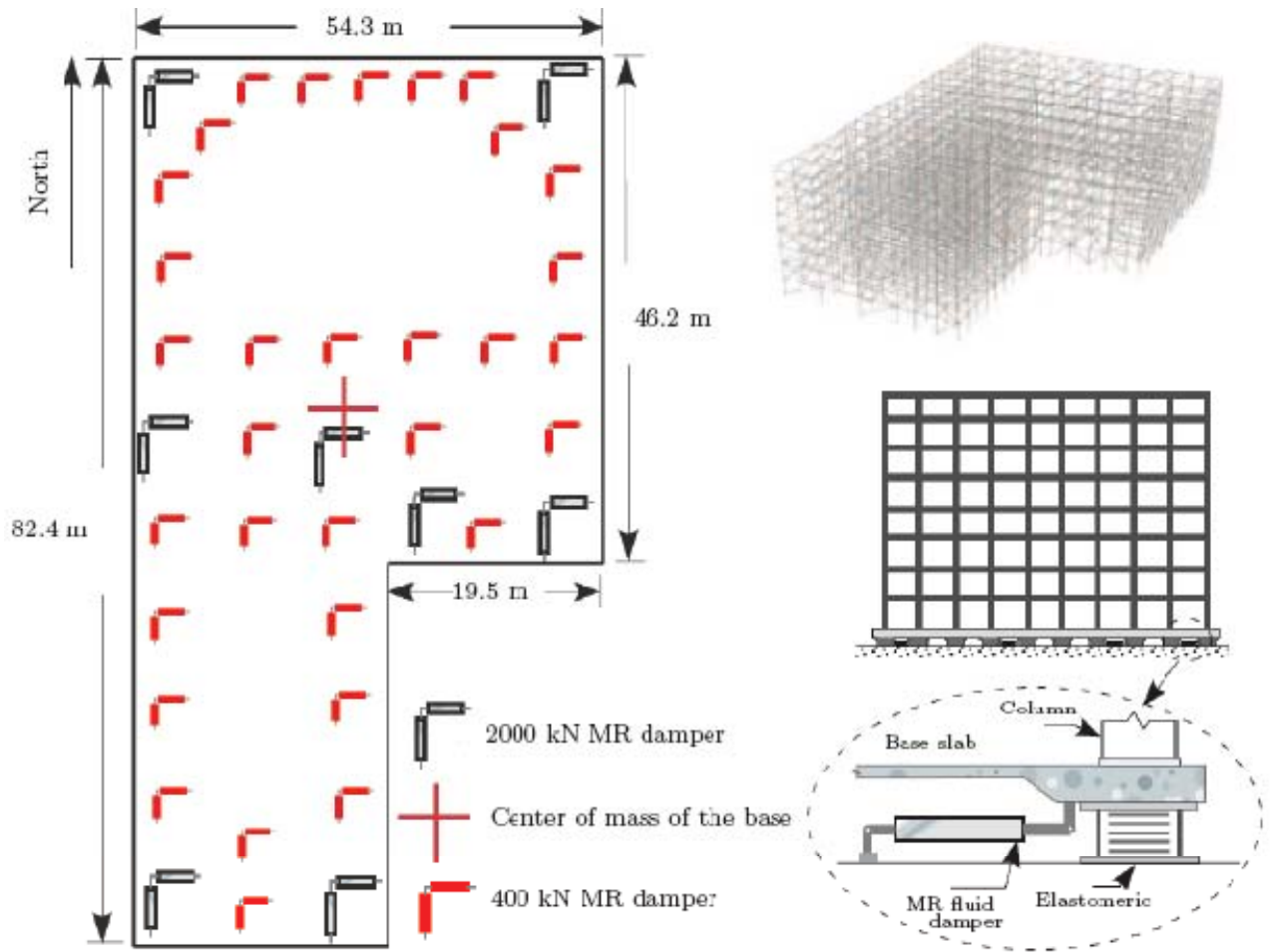

Figure 10. Benchmark base isolated building employing elastomeric rubber bearings and MR fluid dampers (the locations of the 2000 kN MR damper also apply for the 400 kN MR fluid damper).

The MR damper locations are shown in Figure 10, where both the $400 \mathrm{kN}$ and the $2000 \mathrm{kN}$ configurations are shown. The location varies for the $400 \mathrm{kN}$ and the $2000 \mathrm{kN}$ MR dampers. The total number for the $2000 \mathrm{kN}$ MR damper is 16, placed at $n_{M R}=8$ different locations. On the other hand, the $400 \mathrm{kN}$ MR fluid damper total number is 80 , placed at $n_{M R}=40$ different locations. See Figure 12 for a representative figure of the benchmark structure. Seven earthquake records, consisting of fault-parallel 
(FP) and fault-normal (FN) components are prescribed to investigate the effectiveness of the proposed force-derivative feedback semi-active control with passive-off, passive-on and clipped-optimal control. These earthquakes are Newhall, Sylmar, El Centro, Rinaldi, Kobe, JiJi, and Erzinkan. Nine evaluation criteria, $J_{1}, \ldots, J_{9}$, are defined by (Narasimhan et al., 2006). Table IV shows the explanation of these indices.

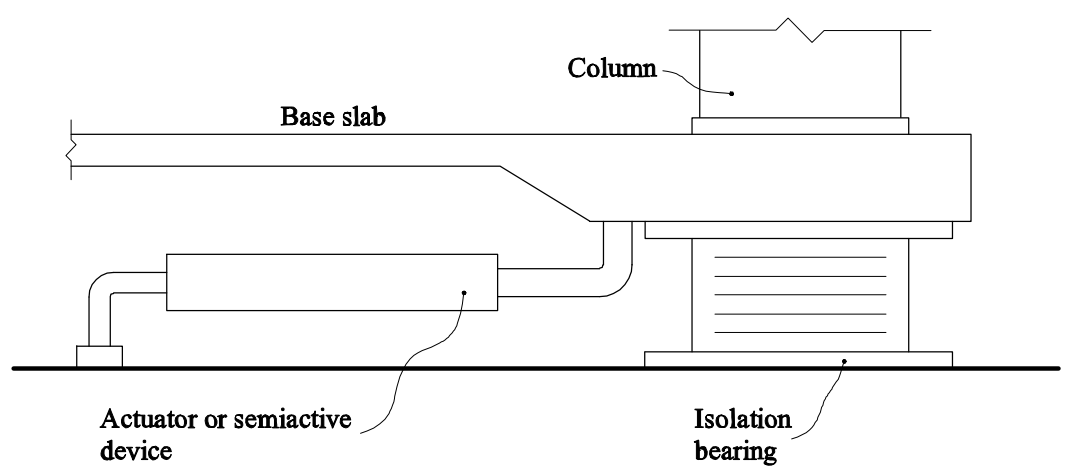

Figure 11. Elevation view with devices.

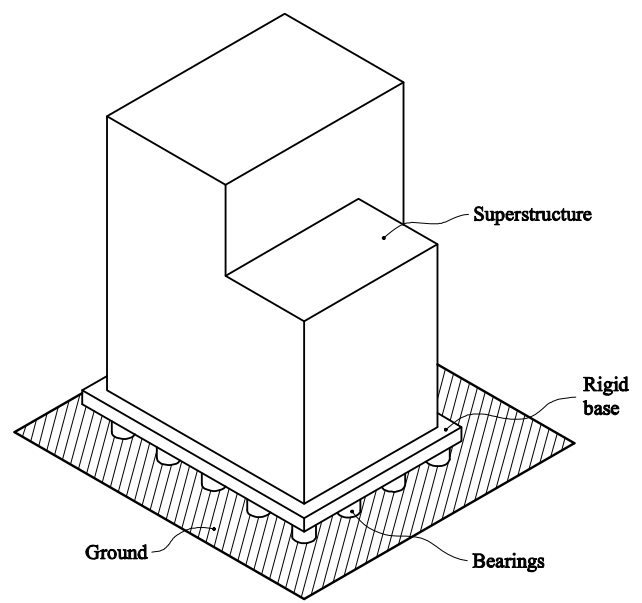

Figure 12. A representative figure of the benchmark structure.

\section{Numerical Results}

The performance of the semi-active control algorithm presented in Section 4 is now evaluated through numerical simulation using the smart base-isolated benchmark building. The results are also compared with the clipped-optimal control algorithm in (Dyke et al., 1996) and also with two limit cases: passive off and passive on, that corresponds to the cases of zero current and maximum current. The evaluation is reported in terms of the performance indices described in Table IV. The controlled benchmark structure is simulated for seven earthquake ground accelerations defined in the benchmark problem (Newhall, Sylmar, El Centro, Rinaldi, Kobe, Ji-Ji and Erzinkan). All the excitations are used at the full intensity for the evaluation of the performance indices. The performance indices larger than 1 indicate that the response of the controlled structure is bigger than that of the uncontrolled structure. The performance indices larger than one in Tables V-VIII are underlined. 
More precisely, Tables V and VI present the evaluation criteria of the benchmark model employing 2000 kN MR dampers for all the seven prescribed earthquakes in two orthogonal directions (a) FP- $x$ and FN- $y$; and (b) FP- $y$ and FN- $x$. The tables make a comparison between the cases of passive-off, passive-off, clipped-optimal, and the proposed semi-active controller. In order to compare the results with existing references of this benchmark study, Tables V and VI present the results for the $2000 \mathrm{kN}$ MR damper. Moreover, it was seen in the simulations that the results from the $400 \mathrm{kN}$ MR fluid damper differs on average between 1-3\% with the $2000 \mathrm{kN}$ MR damper. Table VII shows the average evaluation criteria for all 14 cases shown in Tables V and VI. The total weight of the structure is $W=202000 \mathrm{kN}$, the average story height is $H=4.04 \mathrm{~m}$, and the acceleration due to gravity is $g=9.81 \mathrm{~m} / \mathrm{s}^{2}$.

Table IV. Performance indices, where, $i=$ isolator number, $1, \ldots, n_{M R} ; k=$ device number, $1, \ldots, N_{d} ; f=$ floor number, $1, \ldots, N_{f} ; q=$ earthquake number, $1, \ldots, 7 ; t=$ time, $0 \leq t \leq T_{q} ;$ $\langle\cdot\rangle=$ inner product; $\|\cdot\|=$ vector magnitude incorporating NS and EW components.

\begin{tabular}{lll}
\hline Peak base shear & Peak structure shear & Peak base displacement \\
$J_{1}=\frac{\max _{t}\left\|V_{0}(t, q)\right\|}{\max _{t}\left\|\widehat{V}_{0}(t, q)\right\|}$ & $J_{2}=\frac{\max _{t}\left\|V_{1}(t, q)\right\|}{\max _{t}\left\|\widehat{V}_{1}(t, q)\right\|}$ & $J_{3}=\frac{\max _{t, i}\left\|d_{i}(t, q)\right\|}{\max _{t, i}\left\|\hat{d}_{i}(t, q)\right\|}$ \\
\hline Peak inter-storey drift & Peak Floor acceleration & Peak control force \\
$J_{4}=\frac{\max _{t, f}\left\|d_{f}(t, q)\right\|}{\max _{t, f}\left\|\hat{f}_{f}(t, q)\right\|}$ & $J_{5}=\frac{\max _{t, f}\left\|a_{f}(t, q)\right\|}{\max _{t, f}\left\|\hat{a}_{f}(t, q)\right\|}$ & $J_{6}=\frac{\max _{t}\left\|\sum_{k} F_{k}(t, q)\right\|}{\max _{t}\left\|V_{0}(t, q)\right\|}$ \\
\hline RMS base displacement & RMS floor acceleration & Energy dissipated by MR damper \\
$J_{7}=\frac{\max _{i}\left\|\sigma_{d}(t, q)\right\|}{\max _{i}\left\|\sigma_{\widehat{d}}(t, q)\right\|}$ & $J_{8}=\frac{\max _{f}\left\|\sigma_{a}(t, q)\right\|}{\max _{f}\left\|\sigma_{\widehat{a}}(t, q)\right\|}$ & $J_{9}=\frac{\sum_{k}\left[\int_{\int_{q}}^{T} F_{k}(t, q) v_{k}(t, q) d t\right]}{\int_{0}^{T} q_{\langle}\left(V_{0}(t, q) \dot{U}_{g}(t, q) d t\right)}$ \\
\hline
\end{tabular}

Peak base shear (J1) and structural shear (J2)

The index $J_{1}$ represents the peak base shear (isolation level) in the controlled structure normalized by the corresponding shear in the uncontrolled structure and $J_{2}$ corresponds to the peak structure shear (at first story level) in the controlled structure normalized by the corresponding shear in the uncontrolled structure. It is observed from Tables V and VI that the proposed force-derivative semi-active controller performs better than the clipped-optimal and passive-on and -off cases, except for the Ji-Ji earthquake. This reduction may be perceived in Figures 13, 16 and 17. Even though, for some cases like Ji-Ji, El Centro, and Erzinkan the other control cases might behave slightly better, the performance index does not surpass the value of 1 , which means that it does not amplifies the response. This increment can be seen in Figures 15, 18 and 19. Table VII shows how the average evaluation criteria of the peak base shear and structural shear differ little with each other, and they are below the value of 1 for the $2000 \mathrm{kN}$ MR dampers. Moreover, the Table VIII shows that the average results for the $400 \mathrm{kN}$ MR damper reduce the $J_{1}$ and $J_{2}$ compared to the $2000 \mathrm{kN}$ MR damper configuration.

\section{Peak base displacement (J3)}

The index $J_{3}$ corresponds to the peak base displacement or isolator deformation in the controlled structure normalized by the corresponding displacement in the uncontrolled structure. It is observed from Tables V and VI (Figures 13, 14, 15, 16, 17, 18 and 19) that the passive-off and -on cases achieve much larger displacement reduction compared with the proposed force-derivative semi-active controller. The passive-off archives much larger displacement reduction at all the earthquakes. The Table VIII shows that 
the average results for the $400 \mathrm{kN}$ MR damper reduce $J_{3}$ compared to the $2000 \mathrm{kN}$ MR damper configuration shown in Table VII. Moreover, the performance index does not surpass the value of 1 as seen in Tables VII and VIII.

Table V. 2000kN MR damper evaluation criteria for the proposed semi-active scheme compared with the clipped-optimal control algorithm in (Dyke et al., 1996) and also with two limit cases: passive off and passive on (FP- $x$ and FN-y).

\begin{tabular}{|c|c|c|c|c|c|c|c|c|c|c|c|}
\hline Earthqual & Case & $J_{1}$ & $J_{2}$ & $J_{3}$ & $J_{4}$ & $J_{5}$ & $J_{6}$ & $J_{7}$ & $J_{8}$ & $J_{9}$ & CD \\
\hline \multirow[t]{4}{*}{ Newhall } & Passive-Off & 0.92 & 1.07 & 0.48 & 1.48 & 1.66 & 0.17 & 0.22 & 0.69 & 0.90 & 0.29 \\
\hline & Passi & 0.87 & $\overline{0.90}$ & 0.53 & 1.20 & 1.30 & 0.47 & 0.28 & 0.76 & 0.87 & 0.22 \\
\hline & optimal & 0.85 & 0.85 & 0.57 & $\underline{1.04}$ & $\underline{1.13}$ & 0.35 & 0.34 & 0.70 & 0.82 & 0.19 \\
\hline & Force semi-active & 0.85 & 0.86 & 0.60 & 0.98 & 0.96 & 0.26 & 0.40 & 0.70 & 0.76 & 0.18 \\
\hline \multirow[t]{4}{*}{ Sylmar } & Passive-Off & 0.85 & 0.90 & 0.49 & 0.89 & 1.41 & 0.15 & 0.28 & 0.66 & 0.90 & 0.30 \\
\hline & & 0.75 & 0.77 & 0.60 & 0.74 & 1.11 & 0.51 & 0.36 & 0.62 & 0.87 & 0.27 \\
\hline & optimal & 0.77 & 0.79 & 0.70 & 0.77 & 1.01 & 0.35 & 0.43 & 0.62 & 0.81 & 0.29 \\
\hline & Force semi-active & 0.80 & 0.82 & 0.76 & 0.80 & 0.94 & 0.24 & 0.50 & 0.66 & 0.75 & 0.29 \\
\hline \multirow[t]{4}{*}{ El Centro } & Passive-Off & 0.76 & 0.71 & 0.25 & 0.88 & 1.59 & 0.14 & 0.13 & 0.50 & 0.91 & 0.15 \\
\hline & & 0.80 & 0.74 & 0.31 & 0.68 & 1.22 & 0.51 & 0.17 & 0.56 & 0.88 & 0.12 \\
\hline & C & 0.85 & 0.80 & 0.38 & 0.71 & 0.91 & 0.34 & 0.25 & 0.46 & 0.82 & 0.11 \\
\hline & Forc & 0.87 & 0.85 & 0.42 & 0.74 & 0.88 & 0.35 & 0.34 & 0.49 & 0.75 & 0.11 \\
\hline \multirow[t]{4}{*}{ Rinaldi } & Off & 1.23 & 1.23 & 0.49 & 1.22 & 1.35 & 0.17 & 0.22 & 0.61 & 0.90 & 0.40 \\
\hline & & 1.10 & 1.10 & 0.54 & 1.10 & 1.21 & 0.48 & 0.29 & 0.58 & 0.86 & 0.36 \\
\hline & -optimal & $\underline{1.05}$ & $\underline{1.04}$ & 0.58 & 1.06 & $\underline{1.15}$ & 0.35 & 0.37 & 0.56 & 0.81 & 0.34 \\
\hline & Forc & 1.01 & $\underline{1.01}$ & 0.63 & $\underline{1.03}$ & 1.02 & 0.31 & 0.43 & 0.60 & 0.75 & 0.33 \\
\hline \multirow[t]{4}{*}{ Kobe } & & 0.77 & 0.83 & 0.31 & 1.45 & 2.33 & 0.16 & 0.15 & 0.54 & 0.88 & 0.35 \\
\hline & & 0.77 & 0.76 & 0.37 & 1.13 & 1.66 & 0.53 & 0.19 & 0.70 & 0.86 & 0.27 \\
\hline & -optimal & 0.78 & 0.76 & 0.43 & $\overline{0.93}$ & 1.27 & 0.35 & 0.28 & 0.56 & 0.81 & 0.23 \\
\hline & Force semi-active & 0.79 & 0.77 & 0.47 & 0.84 & 0.99 & 0.31 & 0.37 & 0.56 & 0.75 & 0.21 \\
\hline \multirow[t]{4}{*}{ Jiji } & & 0.64 & 0.64 & 0.45 & 0.68 & 0.81 & 0.11 & 0.30 & 0.52 & 0.73 & 0.32 \\
\hline & & 0.70 & 0.71 & 0.57 & 0.74 & 0.76 & 0.34 & 0.37 & 0.55 & 0.70 & \\
\hline & c & 0.77 & 0.76 & 0.65 & 0.78 & 0.84 & 0.25 & 0.43 & 0.60 & 0.66 & 0.38 \\
\hline & ni-active & 0.81 & 0.81 & 0.70 & 0.82 & 0.84 & 0.18 & 0.48 & 0.65 & 0.62 & 0.39 \\
\hline \multirow[t]{4}{*}{ Erzinkan } & Passive-Off & 0.82 & 0.83 & 0.33 & 0.86 & 1.01 & 0.14 & 0.20 & 0.44 & 0.91 & 0.27 \\
\hline & & 0.76 & 0.77 & 0.40 & 0.80 & 0.91 & 0.46 & 0.28 & 0.45 & 0.87 & 0.26 \\
\hline & & 0.76 & 0.78 & 0.44 & 0.76 & 0.90 & 0.34 & 0.36 & 0.50 & 0.81 & 0.24 \\
\hline & Force semi-active & 0.79 & 0.80 & 0.47 & 0.70 & 0.94 & 0.34 & 0.41 & 0.56 & 0.76 & 0.22 \\
\hline
\end{tabular}

Peak inter-story drift of the superstructure (J4)

The index $J_{4}$ presents the peak inter-story drift in the controlled structure normalized by the corresponding inter-story drift in the uncontrolled structure. It is observed from Tables V and VI that, besides the Ji-Ji earthquake (Figure 18), the proposed force-derivative semi-active controller performs better than the passive and clipped optimal cases. Even though, the peak-interstory drift is amplified by $2 \%$ at the Rinaldi earthquake, the average passive-off case seen in Table VII amplifies the response by 9\%. Moreover, for the Sylmar and El Centro earthquakes (Figure 14 and 15) the response of the proposed force-derivative semi-active control performs better in the FP- $y$ and FN- $x$ than in the FP- $x$ and FN- $y$.

\section{Peak superstructure acceleration (J5)}

The index $J_{5}$ constitutes the peak absolute floor acceleration in the controlled structure normalized by the corresponding acceleration in the uncontrolled structure. It is observed from Tables V and VI that, besides the Ji-Ji earthquake (Figure 18), the proposed force-derivative semi-active controller performs 
better than the passive and clipped optimal cases (Figures 13, 14, 15, 16, 17 and 19). This reduction is quite important for non-structural elements, which may experience significant damage during an earthquake by increased structural accelerations. The proposed controller amplifies the peak structure

Table VI. 2000kN MR damper evaluation criteria for the proposed semi-active scheme compared with the clipped-optimal control algorithm in (Dyke et al., 1996) and also with two limit cases: passive off and passive on (FP-y and FN-x).

\begin{tabular}{|c|c|c|c|c|c|c|c|c|c|c|c|}
\hline Earthqual & Case & $J_{1}$ & $J_{2}$ & $J_{3}$ & $J_{4}$ & $J_{5}$ & $J_{6}$ & $J_{7}$ & $J_{8}$ & $J_{9}$ & CD \\
\hline \multirow[t]{4}{*}{ Newhall } & Passive-Off & 0.84 & 0.92 & 0.49 & 1.48 & 1.65 & 0.16 & 0.30 & 0.71 & 0.89 & 0.45 \\
\hline & Passi & 0.80 & 0.81 & 0.53 & 1.23 & 1.36 & 0.48 & 0.37 & 0.77 & 0.86 & 0.37 \\
\hline & l-optimal & 0.78 & 0.78 & 0.56 & 1.08 & $\underline{1.20}$ & 0.35 & 0.44 & 0.71 & 0.81 & 0.33 \\
\hline & Force semi-active & 0.77 & 0.79 & 0.60 & $\underline{1.02}$ & $\underline{1.01}$ & 0.35 & 0.51 & 0.71 & 0.75 & 0.31 \\
\hline \multirow[t]{4}{*}{ Sylmar } & Passive-Off & 0.72 & 0.76 & 0.52 & 0.89 & 1.08 & 0.15 & 0.30 & 0.48 & 0.91 & 0.36 \\
\hline & & 0.69 & 0.66 & 0.59 & 0.77 & 0.92 & 0.49 & 0.38 & 0.46 & 0.87 & 0.31 \\
\hline & optimal & 0.70 & 0.67 & 0.64 & 0.72 & 0.87 & 0.34 & 0.45 & 0.48 & 0.81 & 0.29 \\
\hline & Force semi-active & 0.71 & 0.69 & 0.72 & 0.69 & 0.82 & 0.24 & 0.53 & 0.53 & 0.75 & 0.29 \\
\hline \multirow[t]{4}{*}{ El Centro } & Passive-Off & 0.74 & 0.76 & 0.37 & 1.26 & 1.89 & 0.13 & 0.18 & 0.53 & 0.91 & 0.15 \\
\hline & & 0.79 & 0.77 & 0.45 & 0.98 & 1.37 & 0.50 & 0.23 & 0.70 & 0.88 & 0.11 \\
\hline & C & 0.84 & 0.83 & 0.55 & 0.86 & 0.95 & 0.33 & 0.34 & 0.60 & 0.82 & 0.10 \\
\hline & Forc & 0.91 & 0.88 & 0.61 & 0.90 & 0.96 & 0.42 & 0.45 & 0.62 & 0.74 & 0.10 \\
\hline \multirow[t]{4}{*}{ Rinaldi } & Off & 1.12 & 1.17 & 0.50 & 1.24 & 1.40 & 0.16 & 0.21 & 0.48 & 0.90 & 0.45 \\
\hline & & 1.01 & 1.06 & 0.55 & 1.13 & 1.25 & 0.46 & 0.27 & 0.42 & 0.86 & 0.41 \\
\hline & l-optimal & 0.96 & $\underline{1.01}$ & 0.60 & 1.08 & 1.17 & 0.34 & 0.35 & 0.42 & 0.81 & 0.40 \\
\hline & Forc & 0.93 & 0.98 & 0.65 & 1.04 & 1.02 & 0.25 & 0.40 & 0.46 & 0.75 & 0.38 \\
\hline \multirow[t]{4}{*}{ Kobe } & & 0.92 & 0.94 & 0.32 & 1.48 & 1.80 & 0.15 & 0.19 & 1.18 & 0.88 & 0.34 \\
\hline & & 0.92 & 0.91 & 0.39 & 1.07 & 1.26 & 0.53 & 0.23 & 0.93 & 0.85 & 0.25 \\
\hline & optimal & 0.94 & 0.93 & 0.44 & $\overline{0.95}$ & $\overline{0.98}$ & 0.35 & 0.32 & 0.75 & 0.81 & 0.21 \\
\hline & Force semi-active & 0.94 & 0.94 & 0.49 & 0.96 & 0.96 & 0.38 & 0.40 & 0.69 & 0.75 & 0.22 \\
\hline \multirow[t]{4}{*}{ Jiji } & & 0.57 & 0.57 & 0.42 & 0.58 & 0.66 & 0.11 & 0.29 & 0.43 & 0.74 & 0.41 \\
\hline & & 0.63 & 0.63 & 0.54 & 0.62 & 0.65 & 0.34 & 0.36 & 0.46 & 0.70 & \\
\hline & ontin & 0.68 & 0.68 & 0.63 & 0.67 & 0.69 & 0.25 & 0.42 & 0.51 & 0.66 & 0.48 \\
\hline & mi-active & 0.71 & 0.71 & 0.70 & 0.71 & 0.73 & 0.19 & 0.49 & 0.56 & 0.61 & 0.49 \\
\hline \multirow[t]{4}{*}{ Erzinkan } & Passive-Off & 0.72 & 0.74 & 0.35 & 0.85 & 0.95 & 0.11 & 0.20 & 0.35 & 0.92 & 0.28 \\
\hline & & 0.68 & 0.69 & 0.41 & 0.74 & 0.81 & 0.46 & 0.25 & 0.36 & 0.88 & 0.26 \\
\hline & & 0.71 & 0.70 & 0.45 & 0.72 & 0.92 & 0.32 & 0.32 & 0.41 & 0.82 & 0.25 \\
\hline & Force semi-active & 0.74 & 0.72 & 0.51 & 0.72 & 0.80 & 0.23 & 0.40 & 0.47 & 0.76 & 0.24 \\
\hline
\end{tabular}

Table VII. Average evaluation criteria for different controllers using 2000 kN MR dampers for earthquake excitations in both directions.

\begin{tabular}{lllllllllll}
\hline Controllers & $J_{1}$ & $J_{2}$ & $J_{3}$ & $J_{4}$ & $J_{5}$ & $J_{6}$ & $J_{7}$ & $J_{8}$ & $J_{9}$ & $\mathrm{CD}$ \\
\hline Passive-Off & 0.83 & 0.86 & 0.41 & $\underline{1.09}$ & $\underline{1.40}$ & 0.14 & 0.23 & 0.58 & 0.88 & 0.32 \\
Passive-On & 0.81 & 0.82 & 0.48 & 0.94 & $\underline{1.15}$ & 0.45 & 0.28 & 0.59 & 0.85 & 0.29 \\
Clipped-optimal & 0.82 & 0.81 & 0.54 & 0.87 & $\underline{1.00}$ & 0.33 & 0.36 & 0.57 & 0.79 & 0.27 \\
Force semi-active & 0.83 & 0.83 & 0.59 & 0.85 & 0.92 & 0.29 & 0.44 & 0.59 & 0.73 & 0.27 \\
\hline
\end{tabular}

acceleration index by a maximum of $7 \%$ for the Rinaldi earthquake (Figure 16). The increment in superstructure acceleration is generally caused by reduction in base displacement of controlled structure due to inherent response spectrum relationship between displacement and acceleration. This is exactly the case for the passive-off, -on, and clipped-optimal cases, which exhibit a base-displacement reduction but 
with a increment in peak structure acceleration. The Table VIII shows that the average results for the 400 $\mathrm{kN}$ MR damper increase slightly $J_{5}$ compared to the $2000 \mathrm{kN}$ MR damper configuration shown in Table VII. Figure 21 shows the response of the proposed force-derivative semi-active controller under the seven

Table VIII. Average evaluation criteria for different controllers using $400 \mathrm{kN}$ for earthquake excitations in both directions.

\begin{tabular}{lllllllllll}
\hline Controllers & $J_{1}$ & $J_{2}$ & $J_{3}$ & $J_{4}$ & $J_{5}$ & $J_{6}$ & $J_{7}$ & $J_{8}$ & $J_{9}$ & $\mathrm{CD}$ \\
\hline Passive-Off & 0.82 & 0.85 & 0.40 & $\underline{1.07}$ & $\underline{1.42}$ & 0.15 & 0.22 & 0.57 & 0.89 & 0.33 \\
Passive-On & 0.79 & 0.80 & 0.47 & 0.92 & $\underline{1.19}$ & 0.46 & 0.28 & 0.57 & 0.87 & 0.30 \\
Clipped-optimal & 0.80 & 0.80 & 0.53 & 0.85 & $\underline{1.02}$ & 0.34 & 0.36 & 0.55 & 0.81 & 0.28 \\
Force semi-active & 0.81 & 0.81 & 0.58 & 0.83 & 0.93 & 0.29 & 0.42 & 0.57 & 0.74 & 0.27 \\
\hline
\end{tabular}

different earthquakes for each performance index. It may be seen that the $J_{5}$ index is amplified for the Rinaldi and Kobe earthquake for the FP- $x$ and FN- $y$ near-fault earthquake direction. Figure 22 shows that, apart from the Rinaldi earthquake, the $J_{5}$ index is amplified for the Newhall earthquake for the FP- $y$ and $\mathrm{FN}-x$ near-fault earthquake direction.

Peak control force (J6)

The index $J_{6}$ represents the peak force generated by all control devices normalized by the peak base shear in the controlled structure. This performance index measures the level of control force with respect to the base shear of the controlled structure. It is observed from Tables V and VI that the $J_{6}$ index has an average value of 0.17 (Figures 13, 14, 15, 16, 17, 18 and 19). This value is below $10000 \mathrm{kN}$ during most loading cases for the semi-active controller. The passive-on case produces a considerable increment in this index establishing a control force above $15000 \mathrm{kN}$. The proposed controller does not require a large control force to reduce base displacements without increasing floor accelerations. Table VIII shows that the average results for the $400 \mathrm{kN}$ MR damper increase slightly $J_{6}$ compared to the $2000 \mathrm{kN}$ MR damper configuration shown in Table VII.

\section{RMS base displacement (J7) and RMS floor acceleration (J8)}

The index $J_{7}$ is the RMS base displacement in the controlled structure normalized by the corresponding RMS base displacement in the uncontrolled structure and the index $J_{8}$ is the RMS absolute floor acceleration in the controlled structure normalized by the corresponding RMS acceleration in the uncontrolled structure. The RMS response quantities are interrelated with the indices $J_{3}$ and $J_{5}$ respectively. It is observed from Tables V and VI that the largest values of $J_{7}$ are achieved by the proposed force-derivative semi-active control case for all earthquakes (Figures 13, 14, 15, 16, 17, 18 and 19). However, as seen in Figures 13, 15 and 17 the proposed force-derivative semi-active control performed better for the $J_{8}$ index than the other control cases. The Table VIII shows that the average results for the $400 \mathrm{kN}$ MR damper reduce $J_{7}$ and $J_{8}$ compared to the $2000 \mathrm{kN}$ MR damper configuration shown in Table VII.

\section{Total controller dissipated energy (J9)}

The index $J_{9}$ constitutes the total energy absorbed by all control devices normalized by energy input into the controlled structure. This evaluation criteria is defined as the ratio of the total energy dissipated by the controllers normalized by the total input energy. It is observed from Tables V and VI that the largest values of $J_{9}$ are achieved by the passive-off case. As seen in Figures 13, 14, 15, 16, 17, 18 and 19 the proposed force-derivative semi-active control case performed better than the other control cases at all earthquakes, which means that the percentage of the input energy dissipated by the device controller is lower than for the passive-off, passive-on, and clipped-optimal control cases. The Table VII shows that 
the average results for the $2000 \mathrm{kN}$ MR damper increase slightly $J_{9}$ compared to the $400 \mathrm{kN}$ MR damper configuration shown in Table VIII.

\section{Corner drift (CD)}

The proposed force-derivative semi-active controller shows the best reduction in corner drifts compared with the other cases, which is approximately $18 \%$ compared with the passive-off case. However, a value of 0.50 for the proposed force-derivative semi-active controller is seen in Table VI for the Ji-Ji earthquake. El Centro earthquake shows the lowest corner drifts compared with the rest of the cases.
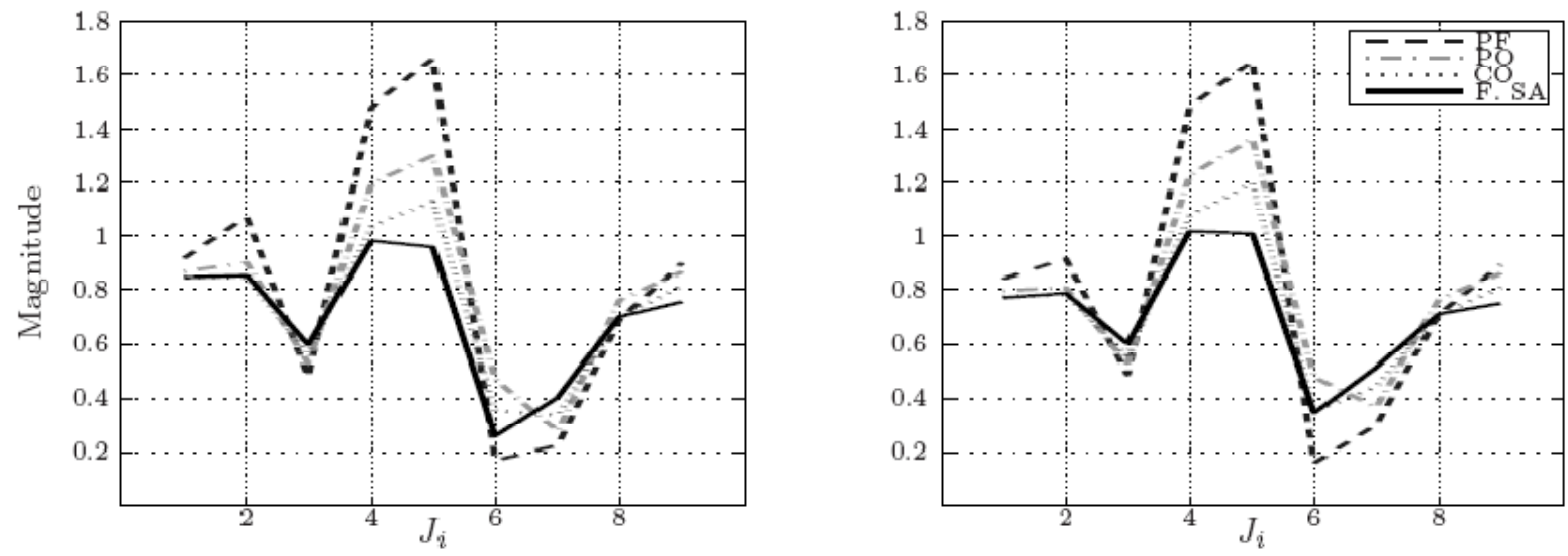

Figure 13. 2000kN MR damper Newhall earthquake response [left (FP-x and FN-y) and right (FP-y and FN- $x$ )]
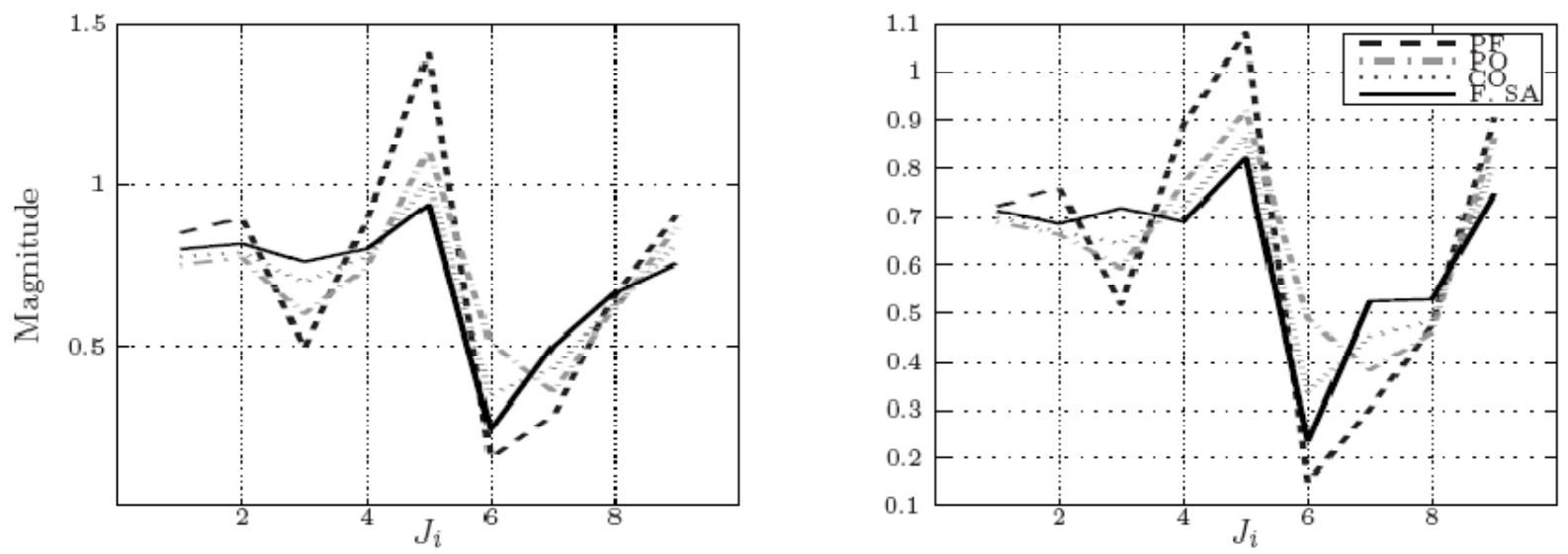

Figure 14. 2000kN MR damper Sylmar earthquake response [left (FP- $x$ and FN-y) and right (FP-y and FN- $x$ )]

Time history plots

Figures 23, 24, 25, 26 and 27 show the time-history response of the base-isolated building under the Erzinkan earthquake for different control cases. The plots represent at the building center of mass the base displacement $(x)$, the eighth floor displacement $\left(x_{8}\right)$, the base acceleration $(\ddot{x})$, the eighth floor acceleration $\left(\ddot{x}_{8}\right)$, and total control force respectively. It is clear in Figure 23 that the proposed semi-active controller reduces the base displacements in $75 \%$ from the passive-off case. However, the uncontrolled 
case will still be $37 \%$ higher than the passive-off case or $75 \%$ from the proposed semi-active controller. Even though, cumulative effects are seen for the proposed semi-active controller in Figure 24, the peak
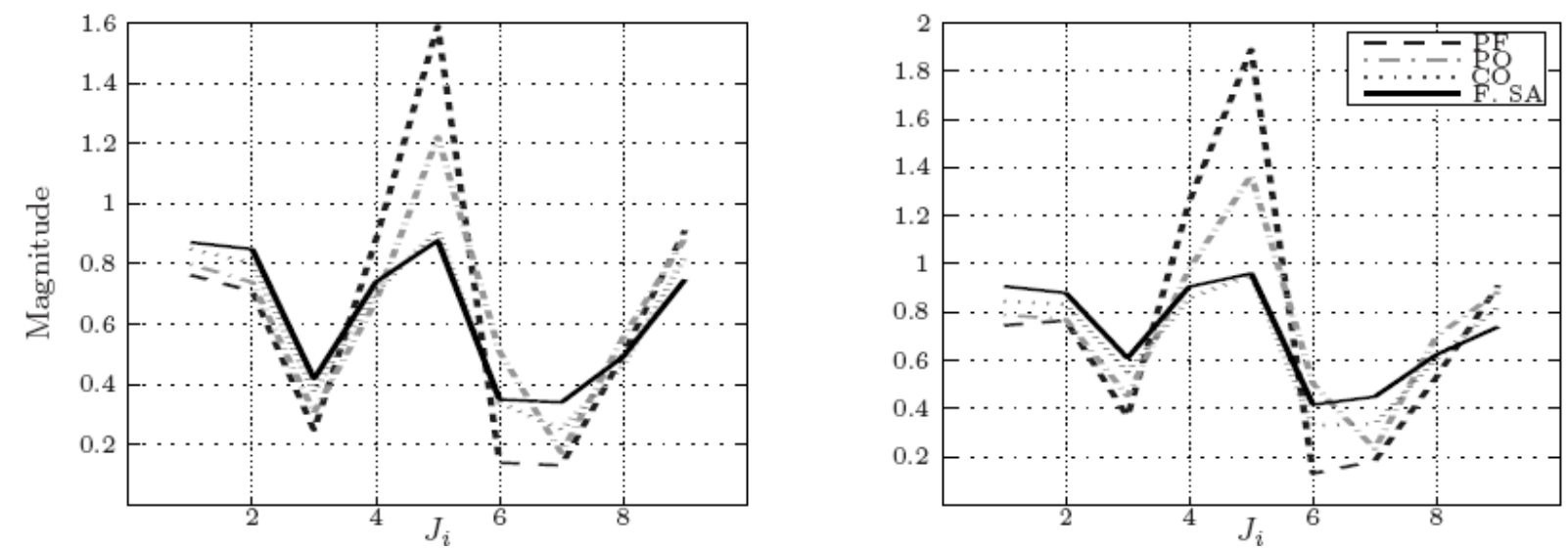

Figure 15. 2000kN MR damper El Centro earthquake response [left (FP- $x$ and FN-y) and right (FP-y and FN- $x$ )]
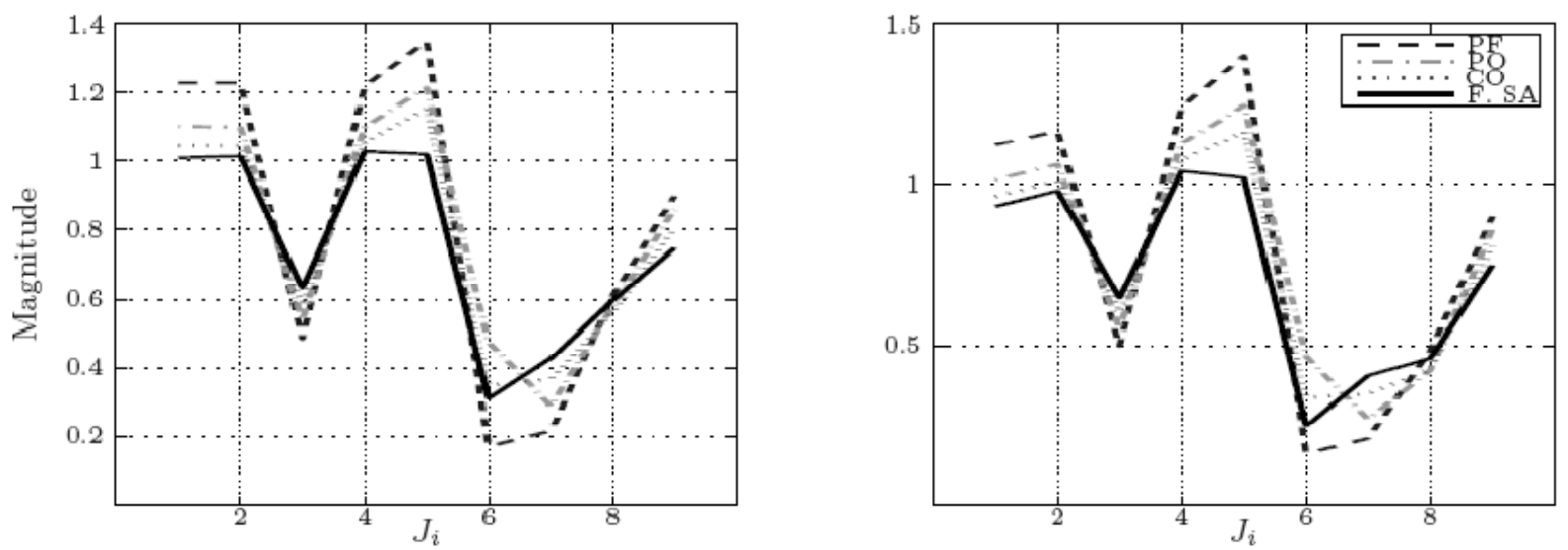

Figure 16. 2000kN MR damper Rinaldi earthquake response [left (FP- $x$ and FN-y) and right (FP-y and FN-x)]

values are quite similar for all cases. Base accelerations seen in Figure 25 are reduced for the proposed semi-active controller compared to its counterparts control cases. The clipped-optimal control case shown in Figure 25 and 26 experiences short-time acceleration increments at certain peaks, which might be due to the high-frequency content of the earthquake excitation. Moreover, peaks higher than $0.2 g$ are seen in Figure 26, where the eighth floor accelerations are increased at the beginning of the earthquake excitation. As seen in Figure 27, the proposed semi-active control uses 30\% less control force than the passive-on case. Moreover, the clipped-optimal control case experiences some chattering at high-periods at low-velocities.

\section{Concluding Remarks}

A force-derivative feedback semi-active control strategy has been presented in this paper, and has been applied to the control of the vibration response of a numerical three-dimensional benchmark building. In the same sense, an experimentally identified large-scale MR fluid damper based on the normalized 
Bouc--Wen model was scale-up in order to test the performance of a real-manufacturable MR damper. A inverse model of an MR damper has also been proposed to overcome the difficulty of commanding the
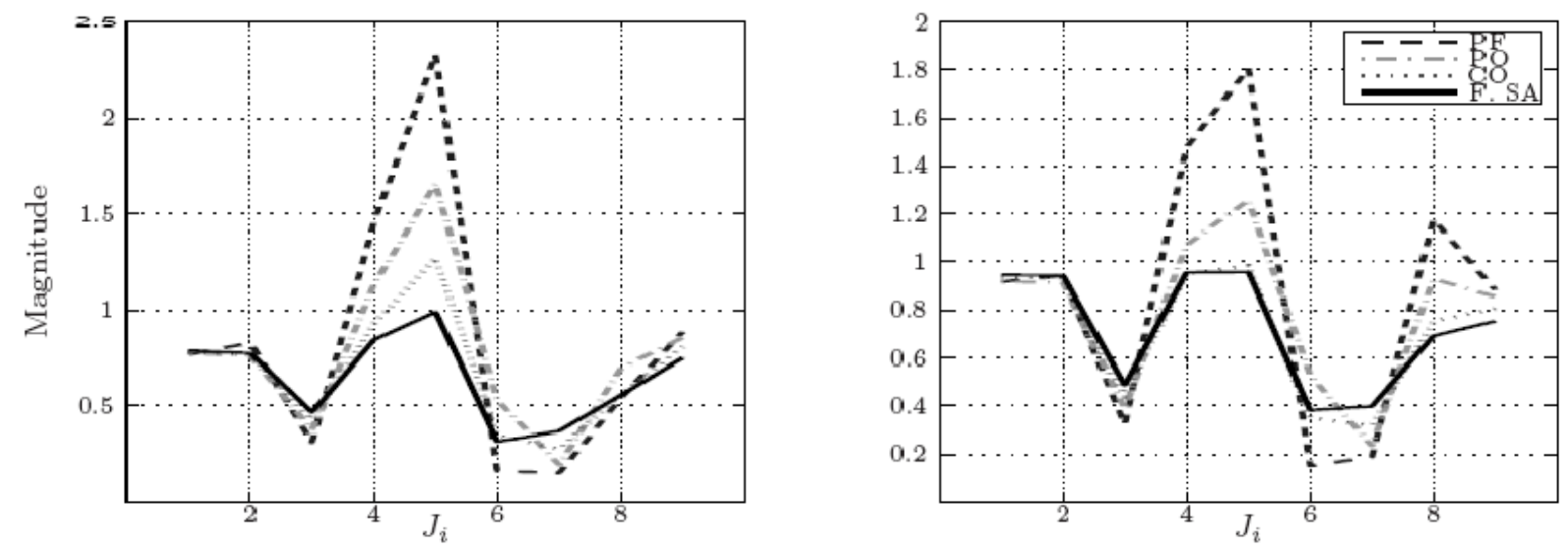

Figure 17. 2000kN MR damper Kobe earthquake response [left (FP- $x$ and FN-y) and right (FP-y and FN- $x$ )]
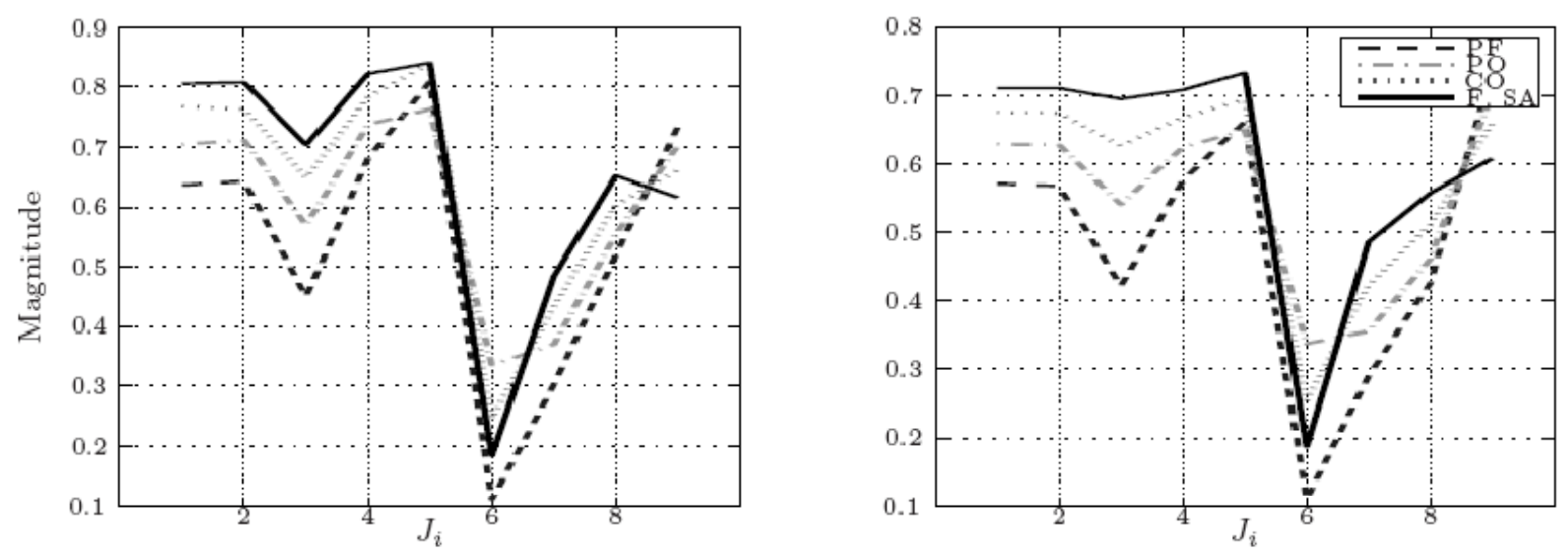

Figure 18. 2000kN MR damper Ji-Ji earthquake response [left (FP- $x$ and FN-y) and right (FP-y and FN-x)]

MR damper to output the desired control force. This inverse model is based on (a) the extended normalized form of the Bouc-Wen model for MR dampers and (b) two simplifications on the parameters of the model. With respect to the implementation issues, a new practical method has been defined to compute the command voltage of each damper independently according to the desired control force: the management of these MR dampers is based on a hierarchical strategy. The whole method is simulated by considering a three-dimensional smart base-isolated benchmark building which is used by the structural control community as a state-of-the-art model for numerical experiments of seismic control attenuation. The performance indices demonstrate that the proposed semi-active method can effectively suppress structural vibration caused by earthquake loading and can provide a desirable effect of structural performance. 

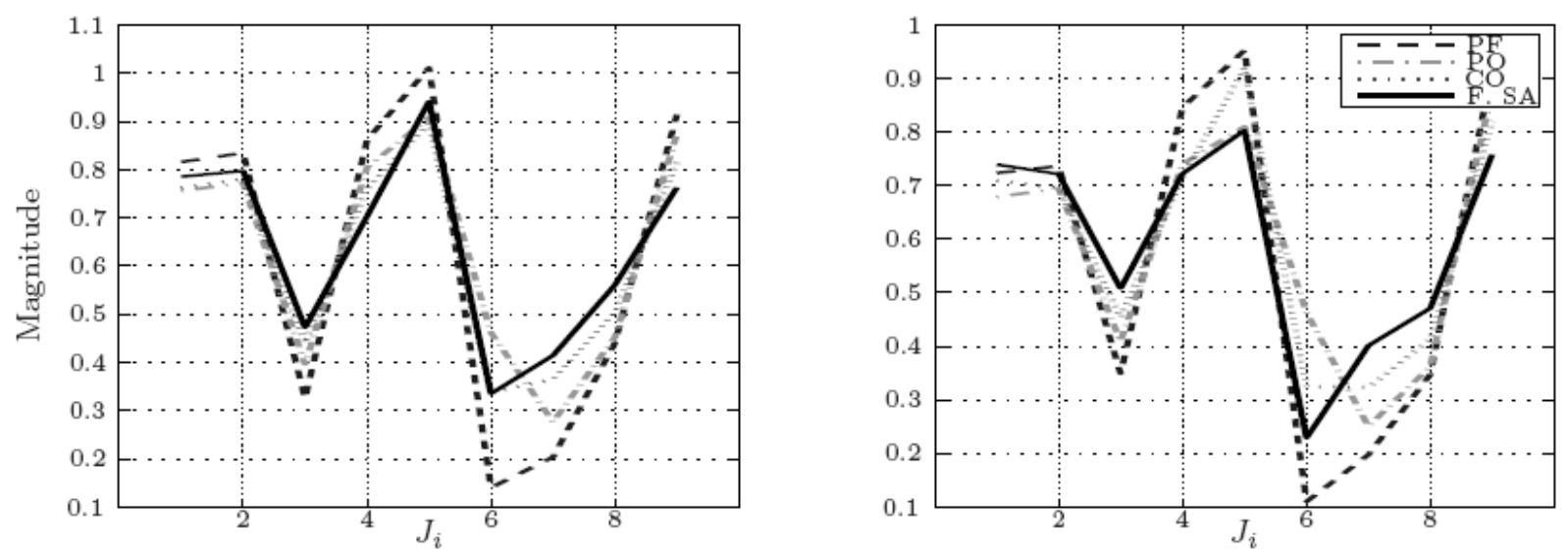

Figure 19. 2000kN MR damper Erzinkan earthquake response [left (FP- $x$ and FN-y) and right (FP-y and FN- $x$ )]
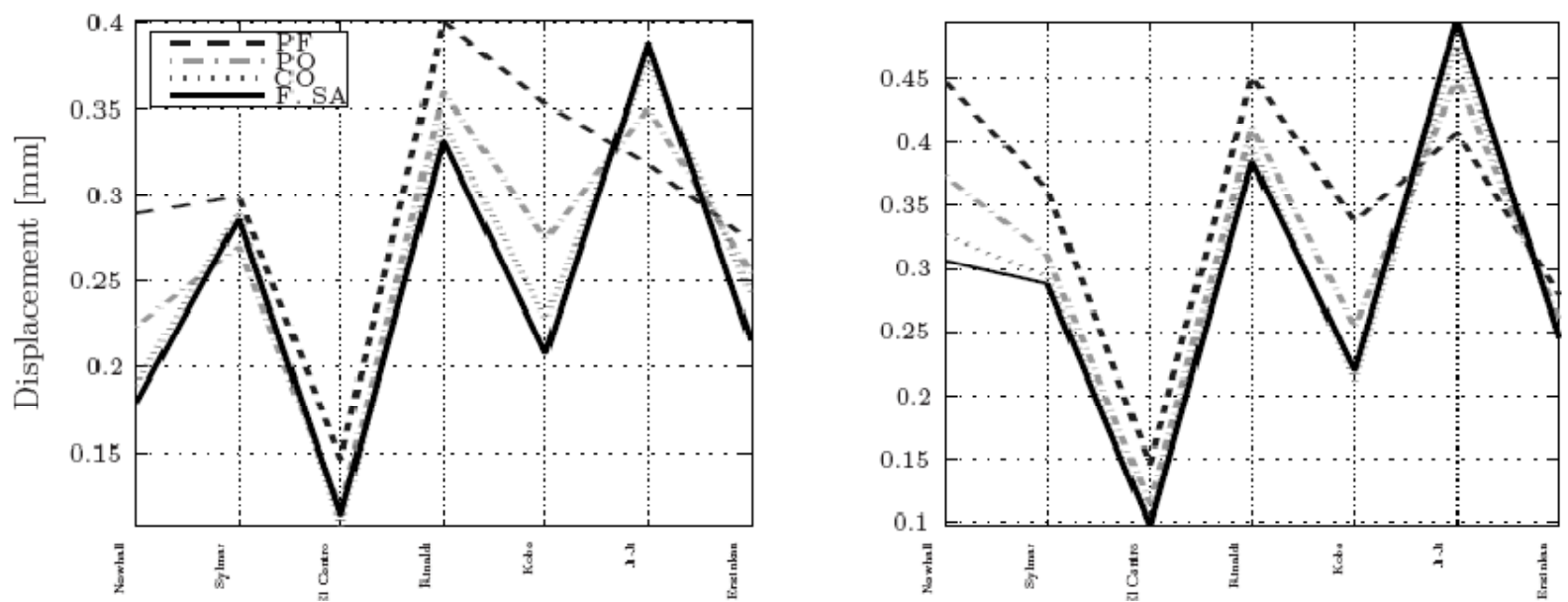

Figure 20. 2000kN MR damper corner drifts [left (FP- $x$ and FN-y) and right (FP- $y$ and FN- $x$ )]

\section{Acknowledgements}

This work is supported by CICYT (Spanish Ministry of Science and Innovation) through grants DPI2008-06463-C02-01 and DPI2008-06564-C02-02. The first author acknowledges the support of the Generalitat de Catalunya and the Agència de Gestió d'Ajuts Universitaris i de Recerca (AGAUR) through the FI and BE fellowships program. The authors would like to thanks Dr. Norio Iwata (Kinki University - Osaka, Japan), Dr. Hideo Fujitani (Kobe University - Kobe, Japan), Dr. Fayçal Ikhouane, and Dr. Alex Barbat and Sergi Arruga for their much-appreciated advice, support, and thought-provoking ideas. 


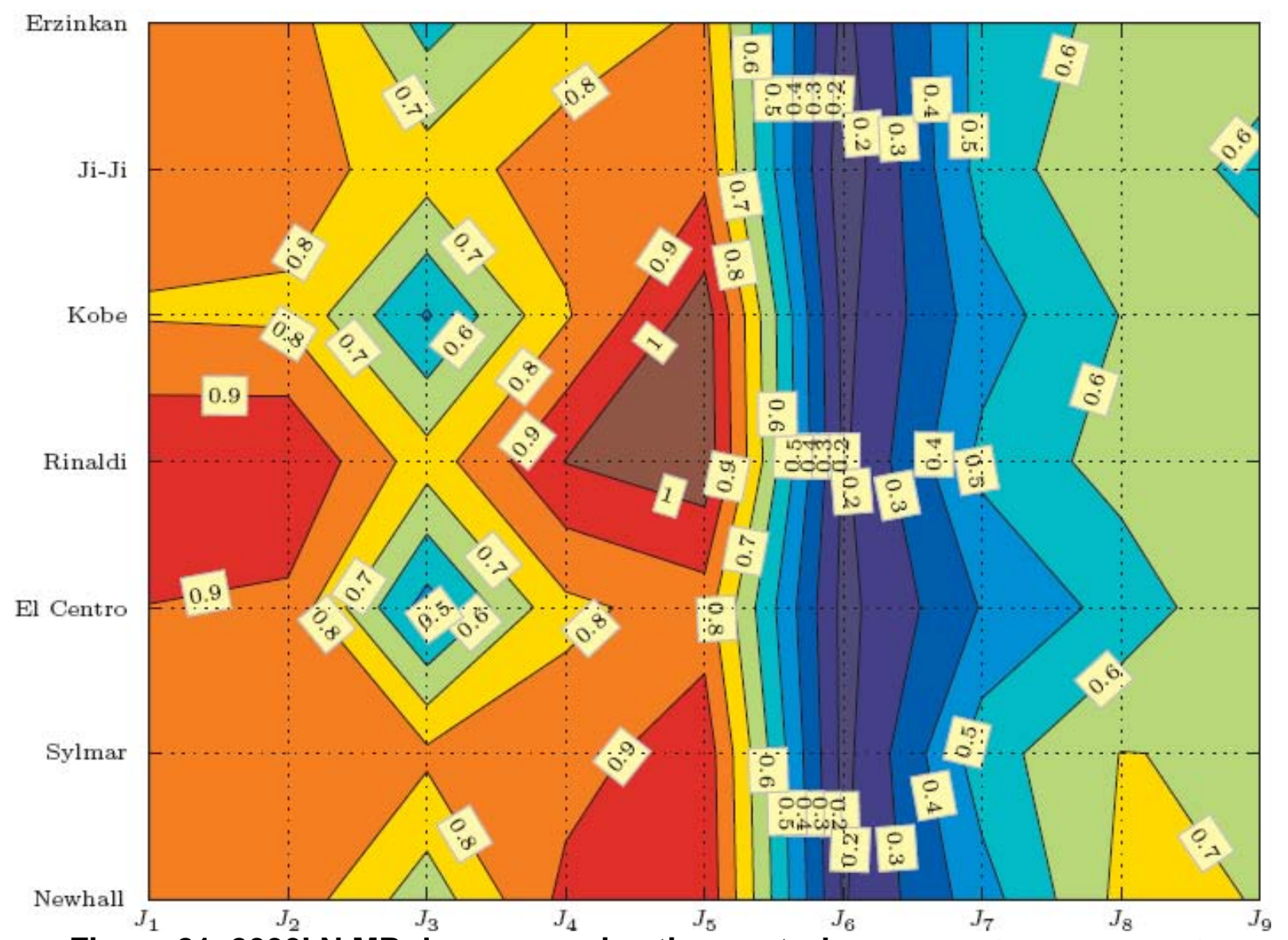

Figure 21. 2000kN MR damper semi-active control response (FP- $x$ and FN- $y$ )

\section{References}

Ahmadizadeh M, Mosqueda G, Reinhorn AM. Compensation of actuator delay and dynamics for real-timehybrid structural simulation. Earthquake Engineering \& Structural Dynamics 2008; 37:21-42.

Alhan C, Gavin HP. Reliability of base isolation for the protection of critical equipment from earthquake hazards. Engineering Structures 2005; 2(2):151-159.

Bahar A, Pozo A, Acho L, Rodellar J, Barbat A. Parameter identification of large-scale magnetorheological dampers in a benchmark building Computers \& Structures 2010a; 88:198-206.

Bahar A, Pozo A, Acho L, Rodellar J, Barbat A. Hierarchical semi-active control of base-isolated structures using a new inverse model of magnetorheological dampers. Computers \& Structures 2010b, 88:483-496.

Benassi L, Elliott SJ, Gardonio P. Active vibration isolation using an inertial actuator with local force feedback control. Journal of Sound and Vibration 2004; 276:157-179.

Bossens F, Preumont A. Active tendon control of cable-stayed bridges: a large-scale demonstration. Earthquake Engineering \& Structural Dynamics 2001; 30:961-979.

Buckingham E. On physically similar systems; Illustrations of the use of dimensional equations. Physical Review 1914; 4(4):345-376.

Carlson JD, Spencer BF. Magnetorheological fluid dampers: Scalability and design issues for application to dynamic hazard mitigation. Proceedings of the 2nd International Workshop on Structural Control 1996; 99-109, Hong Kong.

Dyke SJ, Spencer BF, Sain MK, Carlson JD. Modeling and control of magnetorheological dampers for seismic response reduction. Smart Materials and Structures 1996; 5(5):565-575.

Erkus B, Johnson EA. Smart base-isolated benchmark building Part III: a sample controller for bilinear isolation. Structural Control \& Health Monitoring 2006; 13(2-3):605-625. 


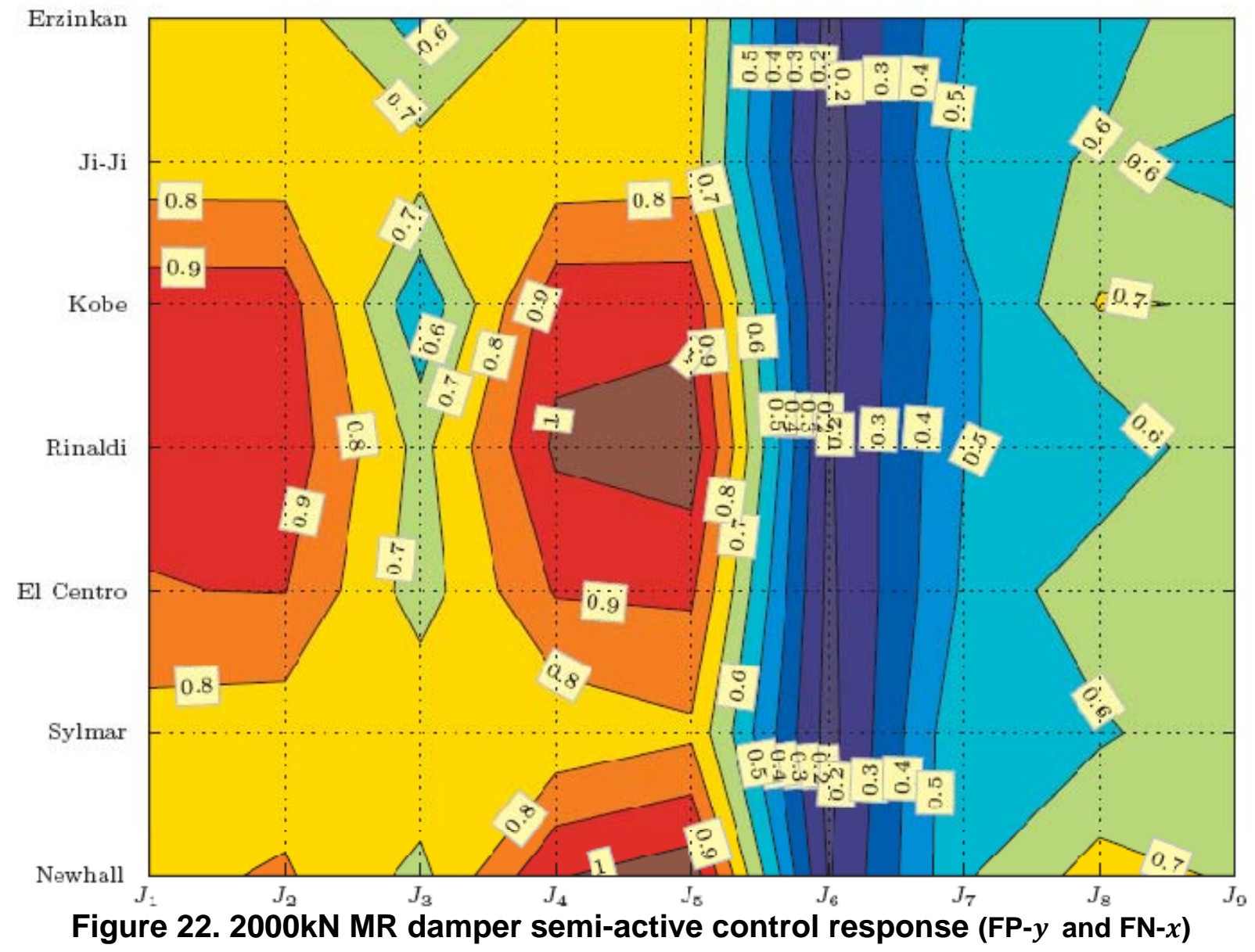

Fujitani H, Sodeyama H, Tomura T, Hiwatashi T, Shiozaki Y, Hata K, Sunkoda K, Morishita S, Soda S. Development of 400kN magnetorheological damper for a real base-isolated building. Proceedings of SPIE - Smart Structures and Materials: Damping and Isolation 2003; 5052: 265-276.

Gavin H, Hoagg J, Dobossy M. Optimal design of MR dampers. Proceedings of the US-Japan Workshop on Smart Structures for Improved Seismic Performance in Urban Regions 2001; Seattle WA, 225-236.

Gu ZQ, Oyadiji SO. Application of MR damper in structural control using ANFIS method. Computers \& Structures 2008; 86(3-5):427-436.

Harris HG, Sabnis G. Structural Modeling and Experimental Techniques. CRC, 1999.

Housner GW, Bergman LA, Caughey TK, Chassiakos AG, Claus RO, Masri SF, Skelton RE, Soong TT, Spencer BF, Yao JTP. Structural control: past, present, and future. Journal of Engineering Mechanics (ASCE) 1997; 123(9):897-971.

Ikhouane F, Hurtado JE, Rodellar J. Variation of the hysteresis loop with the Bouc--Wen model parameters. Nonlinear Dynamics 2007; 48(4):361-380.

Ikhouane F, Mañosa V, Rodellar J. Adaptive control of a hysteretic structural system. Automatica 2005; 41(2):225-231.

Ikhouane F, Rodellar J. Systems with Hysteresis: Analysis, Identification and Control using the Bouc-Wen Model. Wiley: Chichester, 2007.

Jansen LM, Dyke SJ. Semi-active control strategies for MR dampers: A comparative study. Journal of Engineering Mechanics 2000 126(8):795-803.

Jung HJ, Choi KM, Spencer BF, Lee IW. Application of some semi-active control algorithms to a smart base-isolated building employing MR dampers. Structural Control and Health Monitoring 2006; 13(2-3): 693-704.

Kramer SL. Geotechnical Earthquake Engineering. Prentice Hall: Upper Saddle River, New Jersey, 1996.

$\mathrm{Li} \mathrm{H}$, Ou J. A design approach for semi-active and smart base-isolated buildings. Structural Control and Health Monitoring 2006; 13(2-3):660-681.

Luo N, Rodellar J, Vehí J, De la Sen M. Composite semiactive control of a class of seismically excited structures . Journal of the Franklin Institute 2001; 13(2-3):660-681. 


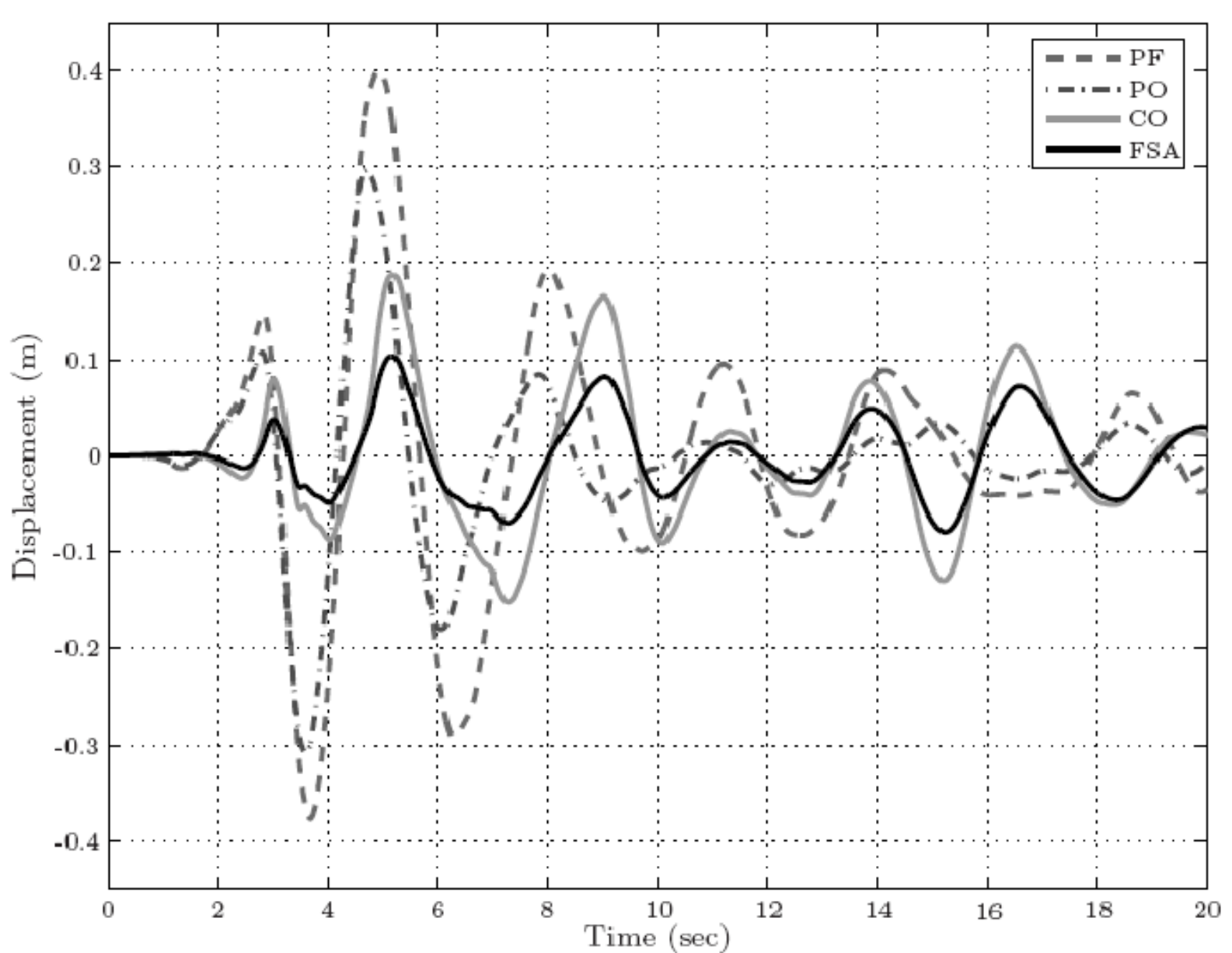

Figure 23. Response time history of the building subjected to Erzinkan earthquake (FP- $y$ and FN- $x$ ) base displacement at the center of mass (2000kN MR damper)

Madden G, Symans MD, Wongprasert N. Experimental verification of seismic response of building frame with adaptive sliding base-isolation system. Journal of Structural Engineering 2002; 128(8):1037-1045.

McClamroch NH, Gavin HP. Closed loop structural control using electrorheological dampers. Proceedings of the American Control Conference 1995; 6:4173-4177.

Naeim F, Kelly JM. Design of Seismic Isolated Structures: From Theory to Practice. John Wiley \& Sons, 1999.

Narasimhan S, Nagarajaiah S, Johnson EA, Gavin HP. Smart base-isolated benchmark building. Part I: problem definition. Structural Control and Health Monitoring 2006; 13(2-3):573-588.

Nagarajaiah S, Narasimhan S. Smart base-isolated benchmark building. Part II: phase I sample controllers for linear isolation systems. Structural Control and Health Monitoring 2006; 13(2-3):589-604.

Ohtori Y, Christenson RE, Spencer BF, Dyke SJ. Benchmark problems in seismically excited nonlinear buildings. Journal of Engineering Mechanics 2004; 130(4):366-385.

Pozo F, Acho L, Rodellar J. Hyperbolic control for vibration mitigation of a base-isolated benchmark structure. Structural Control and Health Monitoring 2009; doi: 10.1002/stc.339.

Pozo F, Ikhouane F, Rodellar J. Adaptive backstepping control of hysteretic base-isolated structures using absolute and relative coordinates. Journal of Vibration and Control 2006; 12(4):373-394.

Pozo F, Montserrat PM, Rodellar J, Acho L. Robust active control of hysteretic base-isolated structures: Application to the benchmark smart base-isolated building. Structural Control and Health Monitoring 2008; 15(5):720-736.

Preumont A, François A, Bossens F, Abu-Hanieh A. Force feedback versus acceleration feedback in active vibration isolation. Journal of Sound and Vibration 2002; 257(4):605-613.

Rodríguez A, Iwata N, Ikhouane F, Rodellar J. Model identification of a large-scale magnetorheological fluid damper. Smart Materials and Structures 2009; 18:1-12. 


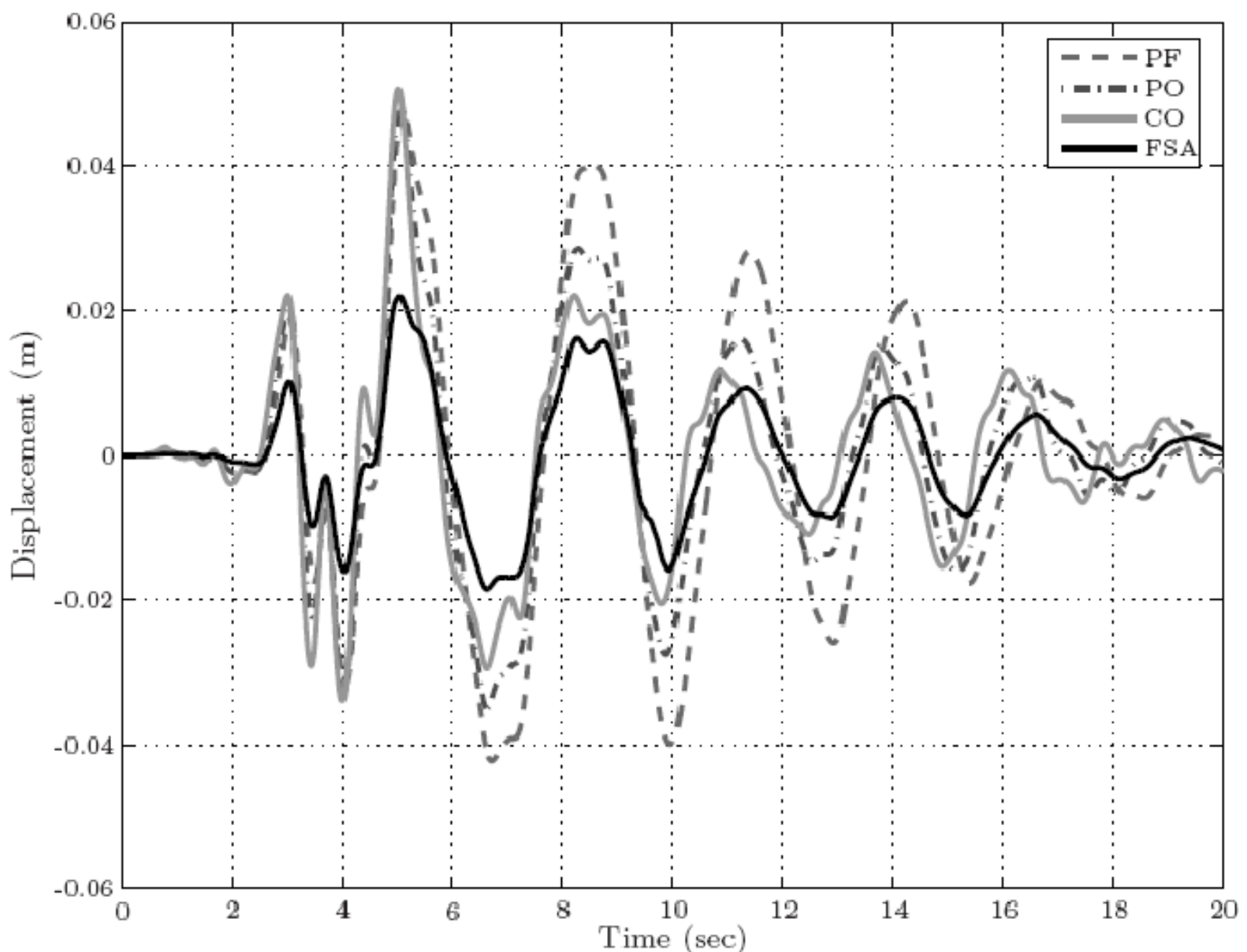

Figure 24. Response time history of the building subjected to Erzinkan earthquake (FP- $y$ and FN- $x) 8^{\text {th }}$ floor displacement at the center of mass (2000kN MR damper)

Songa G, Sethi V, Lic HN. Vibration control of civil structures using piezoceramic smart materials: A review. Engineering Structures 2006; 28(11):1513-1524.

Soong TT, Spencer BF. Supplemental energy dissipation: state-of-the-art and state-of-the-practice. Engineering Structures 2002; 24(3):243-259.

Soong TT, Dargush GF. Passive Energy Dissipation Systems in Structural Engineering. John Wiley and Sons: UK, 1997.

Spencer BF, Nagarajaiah S. State of the art of structural control. Journal of Structural Engineering 2003; 129(7):845-856.

Tsai CS, Chen WS, Chiang TC, Chen BJ. Component and shaking table tests for full-scale multiple friction pendulum system Earthquake Engineering \& Structural Dynamics 2006; 35(13):1653-1675.

Wang ER, Ma XQ, Rakheja S, Su CY. Semi-active control of vehicle vibration with MR dampers. Proceedings of the 42nd IEEE Conference on Decision and Control 2003; Maui, Hawaii, USA.

Wen YK. Method of random vibration of hysteretic systems. ASCE Journal Engineering Mechanics 1976; 102:249-263.

Wu B, Wang Q, Shing PB, Ou J. Equivalent force control method for generalized real-time substructure testing with implicit integration. Earthquake Engineering \& Structural Dynamics 2007; 36(9):1127-1149.

Yoshida O, Dyke SJ. Seismic control of a nonlinear benchmark building using smart dampers. Journal of Engineering Mechanics 2004; 130(4):386-392.

Zapateiro M, Karimi HR,Luo N, Spencer BF. Real-time hybrid testing of semiactive control strategies for vibration reduction in a structure with MR damper. Structural Control and Health Monitoring 2009, doi: 10.1002/stc.321.

Zapateiro M, Luo N, Karimi HR, Vehí J. Vibration control of a class of semiactive suspension system using neural network and backstepping techniques. Mechanical Systems and Signal Processing 2009; 23(6):1946-1953.

Zhao B, Lu X, Wu M, Mei Z. Sliding mode control of buildings with base-isolation hybrid protective system. Earthquake Engineering \& Structural Dynamics 2000; 29(3):315-326. 


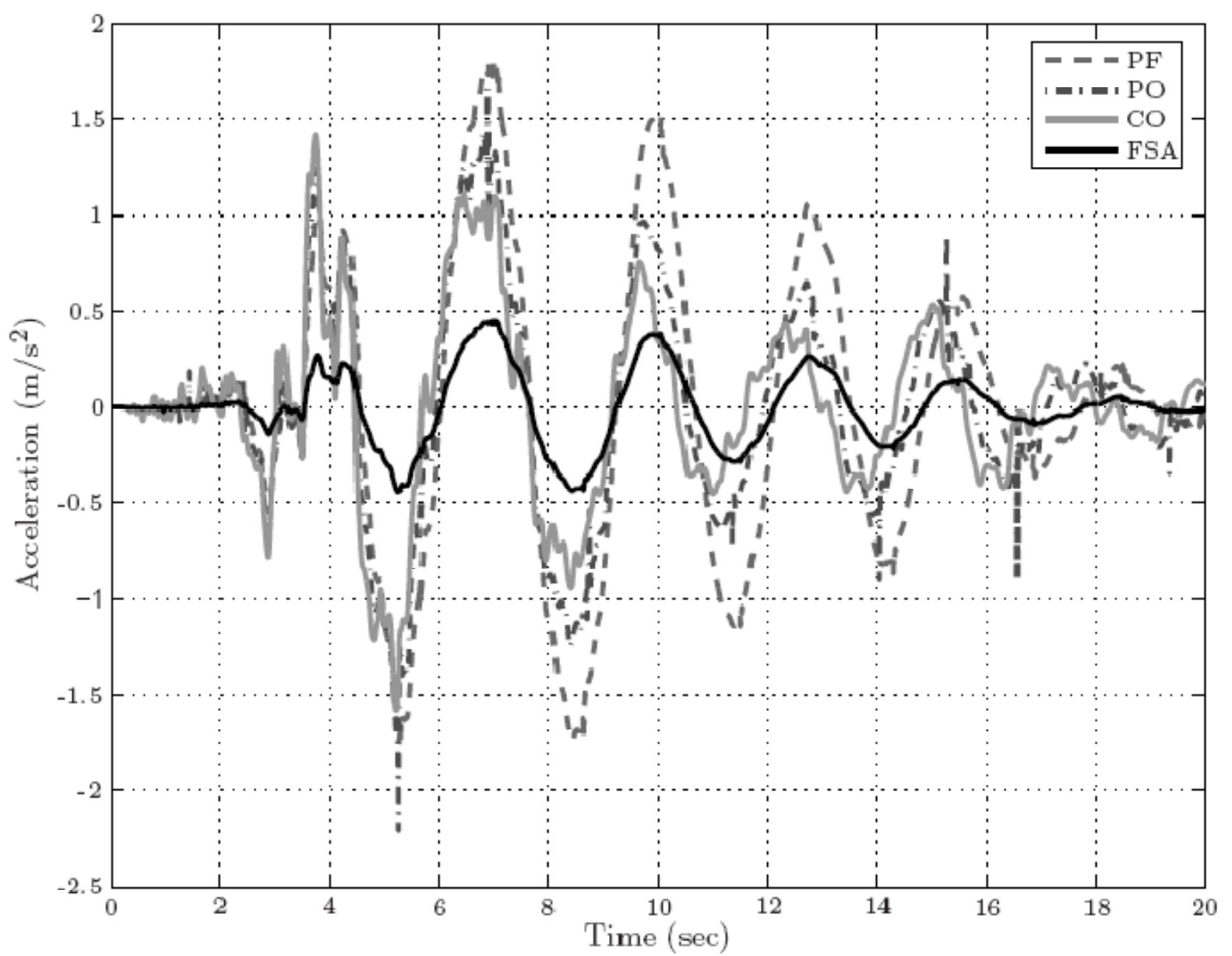

Figure 25. Response time history of the building subjected to Erzinkan earthquake (FP-y and FN- $x$ ) base acceleration at the center of mass (2000kN MR damper) 


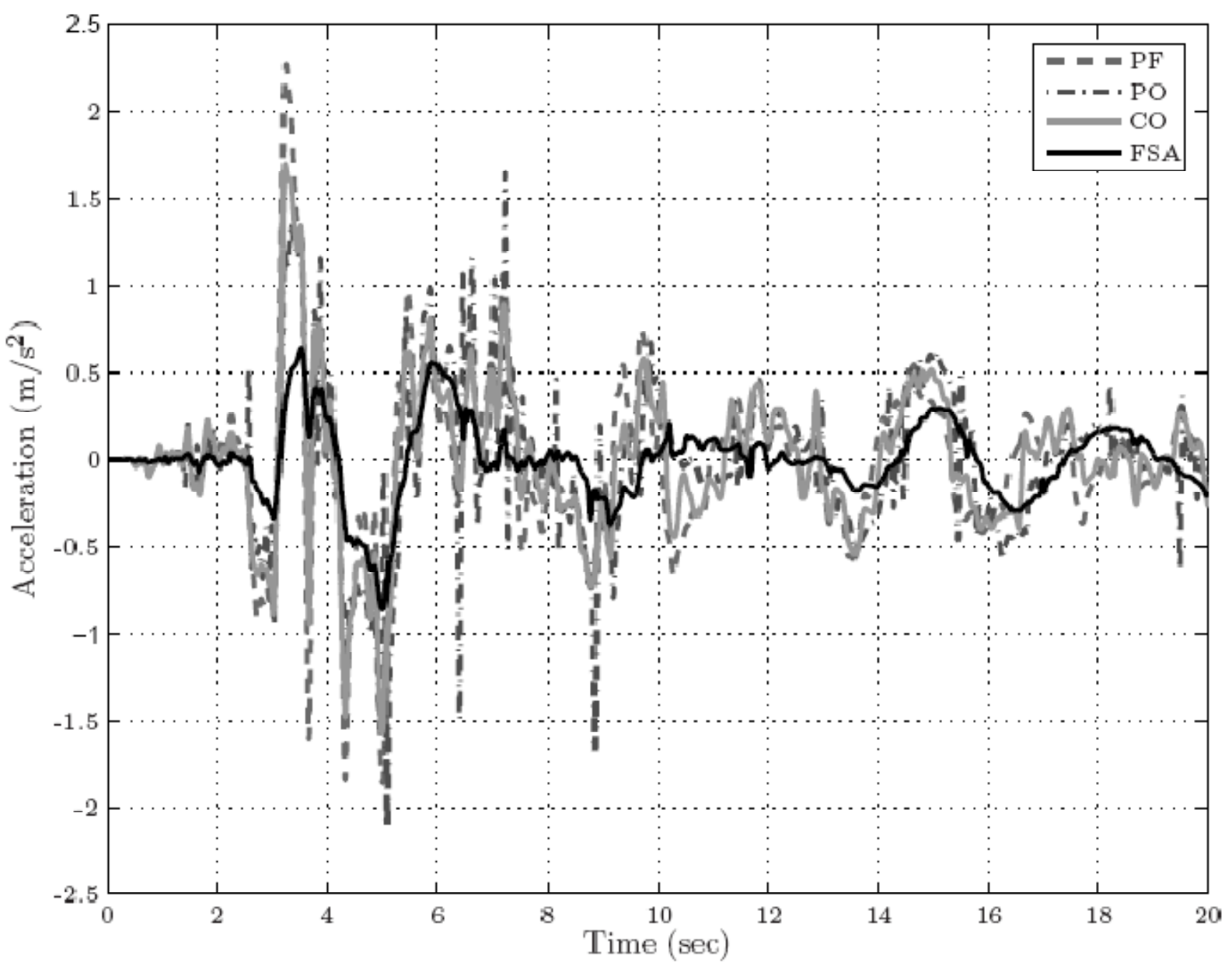

Figure 26. Response time history of the building subjected to Erzinkan earthquake (FP-y and FN- $x$ ) $8^{\text {th }}$ floor acceleration at the center of mass (2000kN MR damper) 


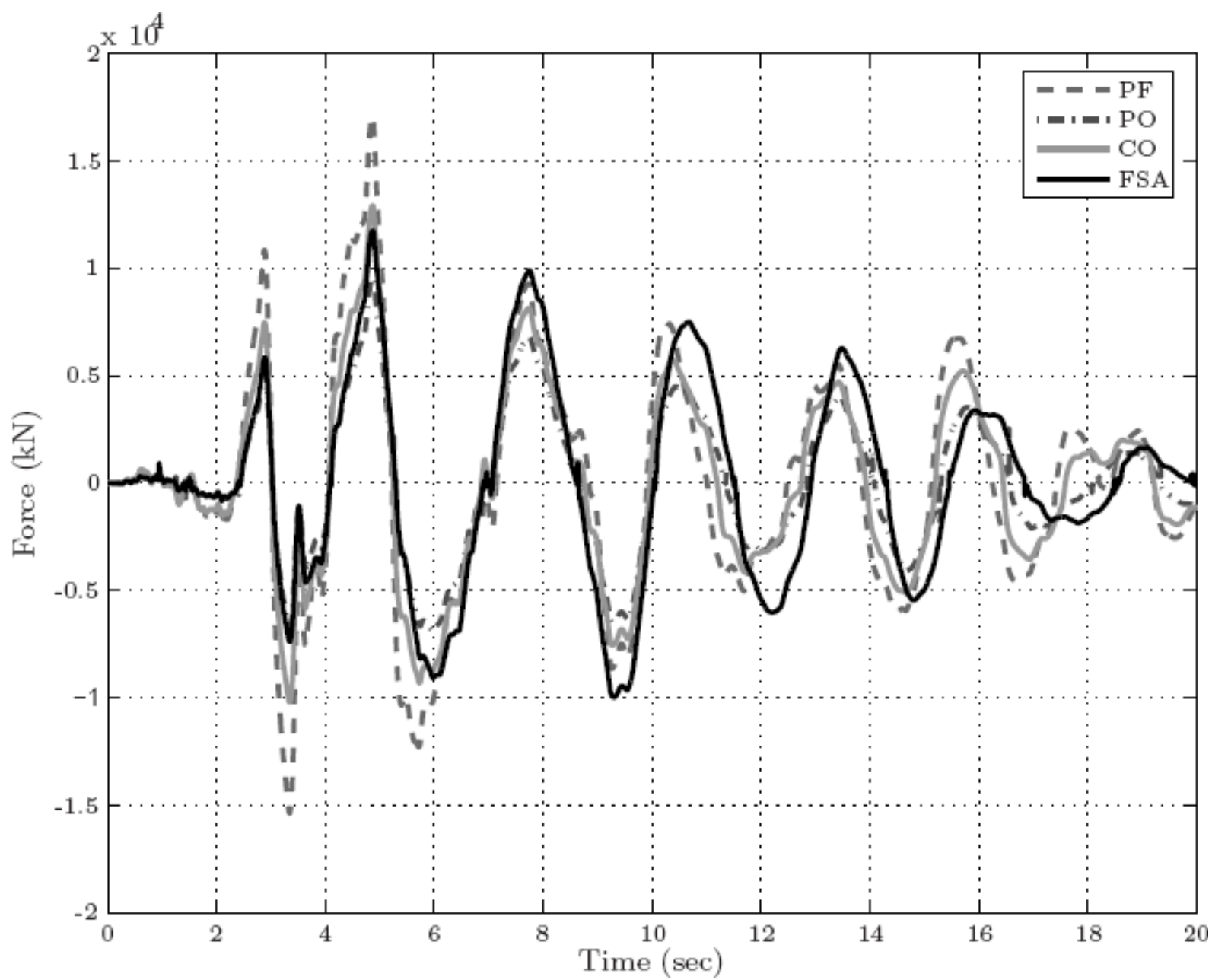

Figure 27. Response time history of the building subjected to Erzinkan earthquake

(FP-y and FN- $x$ ) total control force by the passive-on, clipped-optimal, and proposed semi-active control (2000kN MR damper) 